TITLE:

\title{
A nationwide study of SLE in Japanese identified subgroups of patients with clear signs patterns and associations between signs and age or sex.
}

\section{$\operatorname{AUTHOR}(S):$}

Terao, C; Yamada, R; Mimori, T; Yamamoto, K; Sumida, $T$

\section{CITATION:}

Terao, C ... [et al]. A nationwide study of SLE in Japanese identified subgroups of patients with clear signs patterns and associations between signs and age or sex.. Lupus 2014, 23(13): 1435-1442

\section{ISSUE DATE:}

2014-11

URL:

http://hdl.handle.net/2433/197528

\section{RIGHT:}

(C) The Author(s), 2014. Reprints and permissions:

http://www.sagepub.co.uk/journalsPermissions.nav; This is not the published version. Please cite only the published version.; この論文は出版社版でありません。引用の際には 出版社版をご確認ご利用ください。 
A nationwide study of SLE in Japanese identified subgroups of patients with clear signs patterns and associations between signs and age or sex

Chikashi Terao ${ }^{1,2}$, Ryo Yamada ${ }^{1}$, Tsuneyo Mimori², Kazuhiko Yamamoto ${ }^{3}$, Takayuki Sumida $^{4}$

Chikashi Terao M.D., Ph.D., Ryo Yamada M.D., Ph.D., Tsuneyo Mimori M.D., Ph.D., Kazuhiko Yamamoto M.D., Ph.D., Takayuki Sumida M.D., Ph.D.

${ }^{1}$ Center for Genomic Medicine, ${ }^{2}$ Department of Rheumatology and Clinical Immunology, Kyoto University Graduate School of Medicine, Kyoto, Japan, ${ }^{3}$ Department of Allergy and Rheumatology, Graduate School of Medicine, University of Tokyo, Tokyo, Japan, ${ }^{4}$ Department of Internal Medicine, Faculty of Medicine, University of Tsukuba, Ibaraki, Japan

Correspondence should be addressed to: Ryo Yamada at Center for Genomic Medicine, , Kyoto University Graduate School of Medicine, Kyoto, Japan. Phone number: +81753667403, Fax number: +81757514167, E-mail address: ryamada@genome.med.kyoto-u.ac.jp 


\section{Abstract}

We performed a nation-wide study to determine the distributions of the signs and clinical markers of systemic lupus erythematosus (SLE) and identify any patterns in their distributions to allow patient subclassification. We obtained 256,999 patient-year records describing the disease statuses of SLE patients from 2003 to 2010. Of these, 14,779 involved patients diagnosed within the last year, and 242,220 involved patients being followed-up. Along with basic descriptive statistics, we analyzed the effects of sex, age, and disease duration on the frequencies of signs in the first year and follow-up years. The patients and major signs were clustered using the Ward method. The female patients were younger at onset. Renal involvement and discoid eczema were more frequent in males, whereas arthritis, photosensitivity, and cytopenia were less. Autoantibody production and malar rash were positively associated with young age, and serositis and arthritis were negatively associated. Photosensitivity was positively associated with a long disease duration, and autoantibody production, serositis, and cytopenia were negatively associated. The SLE patients were clustered into sub-groups, as were the major signs. We identified differences in SLE clinical features according to sex, age and disease duration. Subgroups of SLE patients and the major signs of SLE exist. 


\section{Introduction}

Systemic lupus erythematosus (SLE) is an autoimmune disorder that involves multiple organs and can lead to severe complications including cerebral infarction, myocardial infarction, infection, renal failure and a poor prognosis ${ }^{1-4}$. SLE is characterized by the heterogeneity of its clinical features, and we have yet to fully understand this heterogeneity, which is one of the reasons why classification criteria for $\mathrm{SLE}^{5}$ were developed, and new criteria were recently proposed ${ }^{6}$.

\section{Epidemiological studies of SLE}

Epidemiological studies of SLE can be classified into two types. The first type involves studies on relatively detailed issues, including the clinical features of SLE, that only included a limited number of patients. The second type involves studies on limited epidemiological indices, such as the incidence and prevalence of the condition, that included many registrants. Most of the first type of studies were hospital-, clinic- or limited region-based studies with less than 1000 SLE patients ${ }^{7-11}$, although some of these studies recruited participants from multiple regions within a nation ${ }^{12}$. There have only been two national registry-based studies of SLE, which were performed in Taiwan and Japan ${ }^{13,14}$. The sample sizes of these two studies were 22,182 and 21,405, respectively. SLE is three to 10 times more common in females than in males ${ }^{15}$. The age-at-onset of SLE peaks from 15 to 30, and the female:male ratio has been reported to be highest in individuals of reproductive age and decreases in adolescence and old age ${ }^{16}$. While some European studies have reported differences in the age-at-onset between males and females ${ }^{17}$, a relatively large study involving 1,790 cases from China did not detect a significant difference in the mean onset age between the sexes ${ }^{18}$. Thus, it is unclear whether there is no difference in the onset age of SLE between males and females or whether such differences are only observed in Europe.

\section{Signs and clinical markers of SLE}

SLE produces a wide range of clinical signs, including physical signs and laboratory findings. Various reports have detected associations between the clinical features of SLE and age/sex, either at disease onset or throughout the clinical course of the condition. Thus, these reports suggested that age and/or sex can affect the signs of SLE. Efforts have been made to identify subgroups of SLE based on clinical manifestations ${ }^{19,} 20$. However, limited power of previous reports made it difficult to draw conclusions. A detailed analysis of the clinical features of SLE in a large-scale study would increase our understanding of the clinical heterogeneity of SLE. 
Here, we performed a nationwide surveillance study of patients with SLE in Japan to characterize the epidemiological and clinical features of SLE. As far as we know, this is the largest such study to have ever been conducted.

\section{Patients and Methods}

\section{SLE patient registration}

In Japan, a total of 56 diseases are defined as "Nanbyo (Intractable Disease)" and subjected to a questionnaire about their clinical status and history, which is filled in by the clinician providing their care, during registration. The clinicians are not limited to specialists for the diseases. The registered information is used for making decisions by experts on the public financial support provided for their medical care. Each patient is enrolled as a new registrant in the first year after their diagnosis, and their registration is renewed annually by different forms from the first ones (follow-up registry). SLE is one of these "Nanbyo". This registry-based financial support system is well known throughout the country, and Japanese public health departments and healthcare professionals believe that the vast majority of patients with the diseases that receive medical care are registered annually. Clinical information in the questionnaire for SLE forms was listed in Supplementary Table 1.

We obtained text files electronically converted from nationwide registry data about SLE in Japan from 2003 to $2010^{14}$. Although the text files did not cover the all registrants, in total, 14,779 new registries were obtained from 2003 to 2010 and we adopted 2009 (44,249 patients), which covered the largest parts of annual total registries (81.2\%) as a year with representative follow-up data after we found that each year's follow-up registries displayed similar basic statistics. For new registries, we omitted suspected duplicate registries and identified 14,030 registrants as novel for the purposes of this study. We extracted 9,374 registries for which information about disease onset was available and for which it could be confirmed that disease onset had occurred within the last year. Schematic images of quality control of dataset were illustrated in Supplementary Figure 1. We evaluated two patient groups, the first group, which was collected from 2003 to 2010, consisted of patients who had been diagnosed with SLE within the last year, and the other group consisted of all patients in the representative year, 2009. We called these two groups the "novel SLE” and "all SLE” groups, respectively.

\section{Clinical information}


We extracted information about the patients' clinical features including the 11 major signs included in the American College of Rheumatology (ACR) classification ${ }^{5}$, age, sex, age at diagnosis, and complications (infection, bone necrosis, compression fracture of bone, gastric ulcers, myocardial infarction, and cerebral infarction) from the registry for all registrants. Some items including information about anti-nuclear antibody (ANA) positivity, anti-sm antibody positivity, anti-ds DNA antibody positivity, the occurrence of biological false-positives on the syphilis test, lupus anti-coagulant positivity, and anti-cardiolipin antibody positivity were only available for the novel group (Supplementary Table 1).

\section{Sex ratio}

The female:male ratio was estimated in the all SLE group.

\section{Age distribution of SLE patients}

Age-at-onset was compared between males and females in the novel SLE and all SLE groups. The significance of the difference was tested by logistic regression analysis.

\section{Analysis of SLE signs and clinical markers in patients with SLE}

The frequencies of SLE signs and clinical markers were analyzed in the novel and all SLE groups. The effects of age, sex, and disease duration were assessed separately and in combination by multiple logistic regression analysis. Clustering of the major signs and patients was performed in 6,637 patients in the novel SLE group for whom data regarding the 11 major signs and clinical markers were available and 10,000 randomly selected patients in the all SLE group for whom data regarding the 10 major signs and clinical markers other than ANA were available (Supplementary Figure 1). The associations between complications and the patients' basic information, SLE signs and clinical markers were also analyzed. We regarded autoantibody positivity at any point during the disease course as positivity.

\section{Statistical analysis}

Statistical analyses were performed using the R or SPSS (ver18) software.

\section{Results}

\section{Female Ratio of SLE}

The female:male ratio was 8.14 in the all SLE group and was comparable to those described in previous reports $(8.1-12.5)^{21-23}$. A comparison of the age distributions of the 
male and female SLE patients in the all SLE group showed that the females were younger than the males $(p=0.00031$, Figure $1 \mathrm{~A})$. The females were also younger at onset than the males $\left(\mathrm{p}=4.1 \times 10^{-62}\right.$, Figure $\left.1 \mathrm{~B}\right)$.

\section{Prevalence of clinical features and the effects of age and sex on them in the all SLE group}

The prevalences of the 10 major signs of SLE (as outlined by the ACR, except for ANA positivity) varied (Figure 2A, Supplementary Table 2). Cytopenia and arthritis were the two most common signs, and serositis was the least common sign. The frequencies of some of the 10 SLE signs differed markedly between males and females (Figure 2B). An analysis of the effects of age on the frequencies of these signs revealed four patterns, increases with age, decreases with age, a U-shaped age distribution (lowest in middle aged subjects), and an inverse-U shaped age distribution (highest in middle aged subjects) (Figure 2C). An analysis of the effects of disease duration on the frequencies of these signs revealed that most of them were frequently observed in the short duration after onset. The signs' disease duration-based frequency patterns were similar to their age-based patterns. Photosensitivity was the only sign associated with a long disease duration (Figure 2D). Discoid eczema was the only sign that was not associated with disease duration. The detailed results are shown in Supplementary Figure 2 and Supplementary Table 3, and further analyses of the detailed signs of SLE are shown in the Supplementary note and Supplementary Figure 3.

\section{Prevalence of signs and clinical markers and the effects of age and sex on them in the novel SLE group}

The prevalence of the major signs of SLE also varied in the novel SLE patients, and the order of the signs' frequencies (i.e., from highest to lowest) was different from that observed in the all SLE group (Figure 3A and Supplementary Table 2). Except for cytopenia, all of the SLE major signs were affected by sex in the same manner as was observed in the all SLE group according to multiple logistic regression analysis (Figure 2B and 3B and Supplementary Figure 4A). The associations between age and the SLE signs differed between the novel and all SLE groups for four of the 10 items (Figure 2C and 3C and Supplementary Figure 4). Two patterns of difference were observed. The first type involved a positive association with age only being observed in the novel SLE group. The other type involved a positive association with age not being observed in the novel SLE group. Oral ulcers exhibited the former pattern $\left(\mathrm{p}=3.9 \times 10^{-6}\right)$, and renal involvement, cytopenia, and arthritis displayed the latter pattern ( $p>0.019)$. Sex-specific 
age associations showed a third pattern: opposite associations in the novel and all SLE groups. Namely, cytopenia was associated with old age in the males belonging to the novel SLE group, while it was associated with young age in the males in the all SLE group. In addition, three signs showed specific associations with age in the novel SLE group. The frequency of serositis increased age-dependently, whereas the frequencies of renal involvement and arthritis showed $U$ and inverse- $U$ patterns, respectively. The detailed results of the analyses and further analyses are shown in Supplementary Note and Supplementary Table 4.

\section{Clustering analysis of the coexistence of signs and clinical markers in the all SLE and novel SLE groups}

Clustering analysis of the 11 signs in the patients in the novel SLE group revealed that they could be divided into two groups; namely, a group containing autoantibody positivity, ANA positivity, cytopenia, and arthritis and another group including the other 7 signs and markers (Figure 4A). The novel SLE patients $(6,637)$ were also subjected to clustering analysis, which showed that they could be classified into 10 clusters according to their signs (Figure 4B). The sign frequencies and the numbers of SLE patients in each cluster are shown in Supplementary Table 5.

Cluster analysis of the 10 major SLE signs (not including ANA) in the all SLE group showed that they could be sub-grouped into two clusters with the similar characteristics as those observed in the analysis of the novel SLE group although differences were observed among the finer cluster divisions (Figure 4C). Cluster analysis of 10,000 randomly selected SLE patients from the all SLE group produced 8 clear clusters (Figure 4D and Supplementary Table 6). The patterns of clusters partly matched those observed in the novel SLE group.

\section{Further analyses: Complications of SLE and the distributions of specific autoantibodies}

The complications of SLE were also assessed in the all SLE group, as were the effects of age, sex, and disease duration. The associations of autoantibodies with complications were assessed according to age, sex, and disease duration to assess their utility as predictive markers. The associations between complications and each SLE patient cluster were also analyzed. See the Supplementary Notes for details.

\section{Discussion}


Although some small studies did not report a significant difference in age-at-onset between the sexes ${ }^{18}$, our large-scale study demonstrated that female patients developed SLE at a younger age than male patients. We evaluated the clinical features of two patient populations, "the novel patients"; i.e., patients who had been diagnosed with SLE within the last year, and "all patients"; i.e., all patients regardless of their disease duration. As a result, we obtained evidence of associations between SLE signs and age, sex, and disease duration. In our study, the frequencies of 11 major signs were similar to those obtained in previous reports from Asian and European countries in both the novel SLE and all SLE groups with the exception of serositis (25.3\% in novel SLE group, $4.6 \%$ in all SLE group; $5-22 \%$ at onset and $20-40 \%$ prevalence in previous studies) ${ }^{18}$, 23-27. This difference might have been due to the relative difficulty of detecting serositis compared with other features.

We validated previous reports of higher frequencies of serositis ${ }^{28}$, 29 , renal involvement ${ }^{29,} 30$, and discoid eczema ${ }^{29-31}$ in males and higher frequencies of photosensitivity $^{30}$ and oral ulcers ${ }^{30}$ in females. Although neurological involvement was reported to be more common in males in two previous reports ${ }^{32}$, 33 , our study did not find any difference between the sexes. The difference between the sexes in the frequency of malar rash is disputed, and our study did not detect any sex difference. Our results indicate that any inter-sex difference in neurological involvement and malar rash is very small. The sex difference in the frequency of arthritis is also disputed, and we observed a significantly higher frequency of arthritis in females $(47.0 \%$ in females and $36.0 \%$ in males with $\mathrm{p}=1.3 \times 10^{-44}$ ).

Only a few previous studies comprising more than 500 patients have examined the effects of age on the clinical manifestations of SLE 18, 28, 34, 35. Previous studies reported positive associations of younger age with malar rash, discoid eczema, autoantibody production, and photosensitivity ${ }^{18,30}$, and we confirmed these associations. In addition, we demonstrated that serositis and neurological involvement were positively associated with older age. Renal involvement was only associated with younger age in the novel SLE group.

No studies have ever analyzed the detailed effects of disease duration on SLE signs. Most of the major signs and clinical markers of SLE, especially serositis, displayed higher prevalences in the patients with short disease durations. Only the prevalence of photosensitivity increased according to disease duration. Discoid eczema was not associated with disease duration.

We performed similar analyses for more detailed signs of SLE (Supplementary Notes). 
The 11 SLE signs were classified into two groups according to their manifestation patterns in the novel SLE group: group 1 (ANA, autoantibody positivity (anti-sm antibody and anti-dsDNA antibody), cytopenia, and arthritis) and group 2 (malar rash, discoid eczema, photosensitivity, oral ulcers, neurological involvement, serositis, renal involvement). The first group included hematoserological abnormalities such as cytopenia, and arthritis was considered to be an inflammatory/autoimmunity-related reaction and so was classified with the hematoserological abnormalities due to its reduced organ specificity compared to the items in group 2. Therefore, we called group 1 the hematoserological group and group 2 the organ-specific group. In the all SLE group, such clear clustering was not very apparent, which might have been because individual patients tended to present various features during their clinical courses.

The SLE patients in the novel SLE group were clustered into 10 groups according to the signs that they displayed. These groups were not associated with sex, or age (ANOVA, data not shown). At onset, the frequencies of the 10 groups ranged from $4.0 \%$ to $22.4 \%$. The 10 groups were characterized as: represented by (1) neurological involvement (22.4\%), (2) discoid eczema (10.6\%), (3) a lack of autoantibodies other than ANA (12.7\%), (4) oral ulcers (9.1\%), (5) renal involvement (9.9\%), (6) photosensitivity (5.7\%), (7) a lack of arthritis (6.5\%), (8) serositis (9.8\%), (9) malar rash (4.0\%), and (10) others (9.3\%). It should be noted that each group was represented by one of the items in the organ-specific group or a lack of an item in the hematoserological group. These findings suggest that the items in the organ-specific group are the predominant determinants of a patient's condition. In the all SLE group, 8 clusters, which displayed frequencies ranging from 3.9 to $31.5 \%$, were determined. The clusters were characterized as follows: 1 ) no signs or markers (6.9\%), 2) cytopenia alone (5.1\%), 3) autoantibody positivity alone $(3.9 \%), 4)$ cytopenia and autoantibody positivity only (5.9\%), 5) arthritis (9.1\%), 6) renal involvement (16.4\%), 7) neurological signs and serositis (21.3\%), and 8) others (31.5\%). The novel SLE and all SLE groups shared two clusters with similar characteristics; i.e., the "neurological signs": and "renal involvement” clusters. The reduced frequencies of signs and clinical markers observed in the all SLE group led to clusters based on one or no signs. The lack of information about ANA during the chronic phase might also have reduced the number of clusters. We performed five rounds of resampling, each of which involved 10,000 patients, and the same clusters were maintained (data not shown). These results confirm that SLE patients and signs can be subgrouped into clear clusters. However, the 11 or 10 signs of SLE could not consistently explain the division of clusters among different stages of the 
disease. This raised the possibility that underlying factors related to the pathology of SLE other than the 11 signs exist. While we analyzed the associations between clusters and clinical sings or complications, we could not analyze the association between clusters and death due to lack of information. Although the follow-up questionnaire included information of death causes (data not shown), this information was not filled in the most cases. This should be explained by the system of the nation-wide study where patients ask physicians to fill the questionnaire. Associations between clusters in all SLE group and some of complications (Supplementary Notes) suggest the possibility that clusters are associated with severity and prognosis of SLE. Further follow-up studies would clarify the clinical characteristics of the abovementioned clusters.

Finally, we would like to comment on our data source. As the primary purpose of the national registry is to determine whether patients qualify for public financial aid, there could be a bias towards the over-rating of the signs. Despite our concern about such overestimation, the frequencies of individual signs in our study were similar to those described in previous reports from Asian countries ${ }^{36}$, indicating that any over-rating was not too problematic. Considering the number of subjects analyzed in the current study and the fact that the same tendencies were observed in each year (data not shown), our results regarding the patterns of signs and the associations between these signs and gender, age, and disease duration in Japanese SLE patients should be regarded as conclusive.

In conclusion, we have obtained conclusive evidence about the distributions of the clinical features of SLE and their relationships with sex, age, and age-at-onset. 
Funding Acknowledgement. This study was supported by Grants-in-aid from the Ministry of Health, Labor, and Welfare of Japan

Conflicts of interest statement. No conflicts of interest exist.

\section{References}

1. Tsokos GC. Systemic lupus erythematosus. N Engl J Med. 2011; 365: 2110-21.

2. Bengtsson C, Ohman ML, Nived O and Rantapaa Dahlqvist S. Cardiovascular event in systemic lupus erythematosus in northern Sweden: incidence and predictors in a 7-year follow-up study. Lupus. 2012; 21: 452-9.

3. Murray SG, Yazdany J, Kaiser R, et al. Cardiovascular disease and cognitive dysfunction in systemic lupus erythematosus. Arthritis Care Res (Hoboken). 2012; 64: 1328-33.

4. Chiu CC, Huang CC, Chan WL, et al. Increased risk of ischemic stroke in patients with systemic lupus erythematosus: a nationwide population-based study. Intern Med. 2012; 51: 17-21.

5. Hochberg MC. Updating the American College of Rheumatology revised criteria for the classification of systemic lupus erythematosus. Arthritis Rheum. 1997; 40: 1725.

6. Petri M, Orbai AM, Alarcon GS, et al. Derivation and validation of the Systemic Lupus International Collaborating Clinics classification criteria for systemic lupus erythematosus. Arthritis Rheum. 2012; 64: 2677-86.

7. Ward MM. Prevalence of physician-diagnosed systemic lupus erythematosus in the United States: results from the third national health and nutrition examination survey. $J$ Womens Health (Larchmt). 2004; 13: 713-8.

8. Amor B, Bouchet $\mathrm{H}$ and Delrieu F. [National survey on reactive arthritis by the French Society of Rheumatology]. Rev Rhum Mal Osteoartic. 1983; 50: 733-43.

9. Gudmundsson S and Steinsson K. Systemic lupus erythematosus in Iceland 1975 through 1984. A nationwide epidemiological study in an unselected population. J Rheumatol. 1990; 17: 1162-7.

10. Somers EC, Thomas SL, Smeeth L, Schoonen WM and Hall AJ. Incidence of systemic lupus erythematosus in the United Kingdom, 1990-1999. Arthritis Rheum. 2007; 57: $612-8$.

11. Helve T. Prevalence and mortality rates of systemic lupus erythematosus and causes of death in SLE patients in Finland. Scand J Rheumatol. 1985; 14: 43-6.

12. Hiraki LT, Feldman CH, Liu J, et al. Prevalence, incidence, and demographics of 
systemic lupus erythematosus and lupus nephritis from 2000 to 2004 among children in the US Medicaid beneficiary population. Arthritis Rheum. 2012; 64: 2669-76.

13. Chiu YM and Lai CH. Nationwide population-based epidemiologic study of systemic lupus erythematosus in Taiwan. Lupus. 2010; 19: 1250-5.

14. Ohta A, Nagai M, Nishina M, Tomimitsu H and Kohsaka H. Age at onset and gender distribution of systemic lupus erythematosus, polymyositis/dermatomyositis, and systemic sclerosis in Japan. Modern rheumatology / the Japan Rheumatism Association. 2012.

15. Pons-Estel GJ, Alarcon GS, Scofield L, Reinlib L and Cooper GS. Understanding the epidemiology and progression of systemic lupus erythematosus. Semin Arthritis Rheum. 2010; 39: 257-68.

16. Lahita RG. The role of sex hormones in systemic lupus erythematosus. Curr Opin Rheumatol. 1999; 11: 352-6.

17. Lu LJ, Wallace DJ, Ishimori ML, Scofield RH and Weisman MH. Review: Male systemic lupus erythematosus: a review of sex disparities in this disease. Lupus. 2010; 19: 119-29.

18. Feng JB, Ni JD, Yao X, et al. Gender and age influence on clinical and laboratory features in Chinese patients with systemic lupus erythematosus: 1,790 cases. Rheumatol Int. 2010; 30: 1017-23.

19. Levy DM, Peschken CA, Tucker LB, et al. Influence of ethnicity on childhood-onset systemic lupus erythematosus: results from a multiethnic multicenter Canadian cohort. Arthritis Care Res (Hoboken). 2013; 65: 152-60.

20. Jacobsen S, Petersen J, Ullman S, et al. A multicentre study of 513 Danish patients with systemic lupus erythematosus. I. Disease manifestations and analyses of clinical subsets. Clin Rheumatol. 1998; 17: 468-77.

21. Pons-Estel BA, Catoggio LJ, Cardiel MH, et al. The GLADEL multinational Latin American prospective inception cohort of 1,214 patients with systemic lupus erythematosus: ethnic and disease heterogeneity among "Hispanics". Medicine. 2004; 83: 1-17.

22. Ballou SP, Khan MA and Kushner I. Clinical features of systemic lupus erythematosus: differences related to race and age of onset. Arthritis Rheum. 1982; 25: $55-60$.

23. Wang F, Wang CL, Tan CT and Manivasagar M. Systemic lupus erythematosus in Malaysia: a study of 539 patients and comparison of prevalence and disease expression in different racial and gender groups. Lupus. 1997; 6: 248-53.

24. Tan TC, Fang H, Magder LS and Petri MA. Differences between male and female systemic lupus erythematosus in a multiethnic population. J Rheumatol. 2012; 39: 759-69. 
25. Garcia MA, Marcos JC, Marcos AI, et al. Male systemic lupus erythematosus in a Latin-American inception cohort of 1214 patients. Lupus. 2005; 14: 938-46.

26. Malaviya AN, Chandrasekaran AN, Kumar A and Shamar PN. Systemic lupus erythematosus in India. Lupus. 1997; 6: 690-700.

27. Chahade WH, Sato EI, Moura JE, Jr., Costallat LT and Andrade LE. Systemic lupus erythematosus in Sao Paulo/Brazil: a clinical and laboratory overview. Lupus. 1995; 4: 100-3.

28. Cervera R, Khamashta MA, Font J, et al. Systemic lupus erythematosus: clinical and immunologic patterns of disease expression in a cohort of 1,000 patients. The European Working Party on Systemic Lupus Erythematosus. Medicine. 1993; 72: 113-24.

29. Soto ME, Vallejo M, Guillen F, Simon JA, Arena E and Reyes PA. Gender impact in systemic lupus erythematosus. Clin Exp Rheumatol. 2004; 22: 713-21.

30. Voulgari PV, Katsimbri P, Alamanos Y and Drosos AA. Gender and age differences in systemic lupus erythematosus. A study of 489 Greek patients with a review of the literature. Lupus. 2002; 11: 722-9.

31. Font J, Cervera R, Navarro M, et al. Systemic lupus erythematosus in men: clinical and immunological characteristics. Ann Rheum Dis. 1992; 51: 1050-2.

32. Stefanidou S, Benos A, Galanopoulou V, et al. Clinical expression and morbidity of systemic lupus erythematosus during a post-diagnostic 5-year follow-up: a male:female comparison. Lupus. 2011; 20: 1090-4.

33. Mok CC, To CH, Ho LY and Yu KL. Incidence and mortality of systemic lupus erythematosus in a southern Chinese population, 2000-2006. J Rheumatol. 2008; 35: 1978-82.

34. Ward MM and Polisson RP. A meta-analysis of the clinical manifestations of older-onset systemic lupus erythematosus. Arthritis Rheum. 1989; 32: 1226-32.

35. Lalani S, Pope J, de Leon F and Peschken C. Clinical features and prognosis of late-onset systemic lupus erythematosus: results from the 1000 faces of lupus study. $J$ Rheumatol. 2010; 37: 38-44.

36. Jakes RW, Bae SC, Louthrenoo W, Mok CC, Navarra SV and Kwon N. Systematic review of the epidemiology of systemic lupus erythematosus in the Asia-Pacific region: prevalence, incidence, clinical features, and mortality. Arthritis Care Res (Hoboken). 2012; 64: $159-68$.

Figure 1. Distribution of patients who developed SLE

A) Distribution of the current ages of the SLE patients.

B) Distribution of the age-at-onset of the SLE patients. 
Figure 2. Distribution and clusters of SLE signs and patients in the all SLE group A) Frequency of SLE signs in a year.

Frequencies of SLE signs according to sex (B), age (C), and disease duration (D). ${ }^{*}$ p-value $<10^{-5}, * *$ p-value $<10^{-10}$

Figure 3. Distribution and clusters of SLE signs and patients in the novel SLE group

A) Frequencies of SLE signs during the first year after diagnosis.

Frequency of SLE signs within a year of diagnosis according to sex (B) and age (C) based on multiple logistic linear regression analysis. ${ }^{*}$ p-value $<10^{-5}, * *$ p-value $<10^{-10}$

Figure 4. Clusters of SLE signs and patients.

A) Clustering of 11 SLE major signs in patients that had been diagnosed with SLE within the last year.

B) Clustering of 6637 SLE patients that had been diagnosed with SLE within the last year.

C) Clustering of 10 major SLE signs in the all SLE group.

D) Clustering of 10,000 SLE patients in the all SLE group. 
A
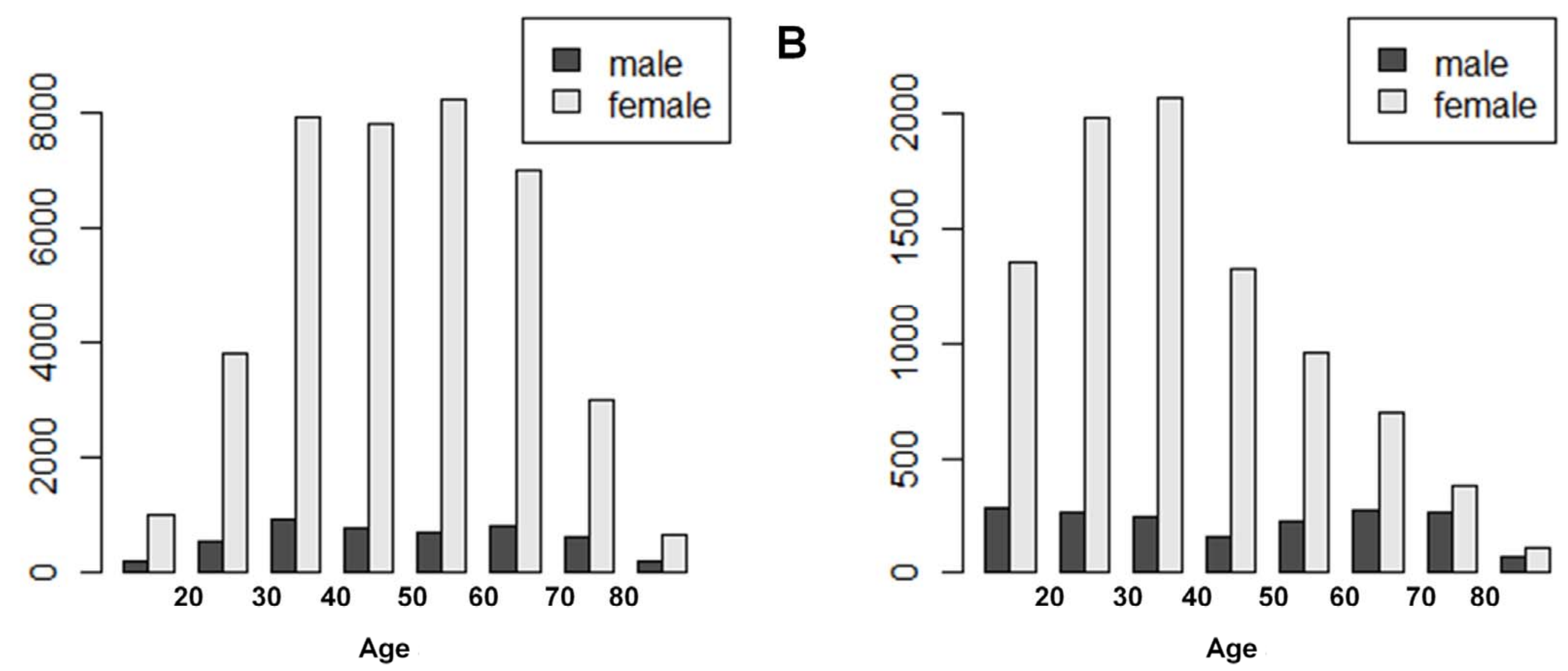

Figure 1 
A

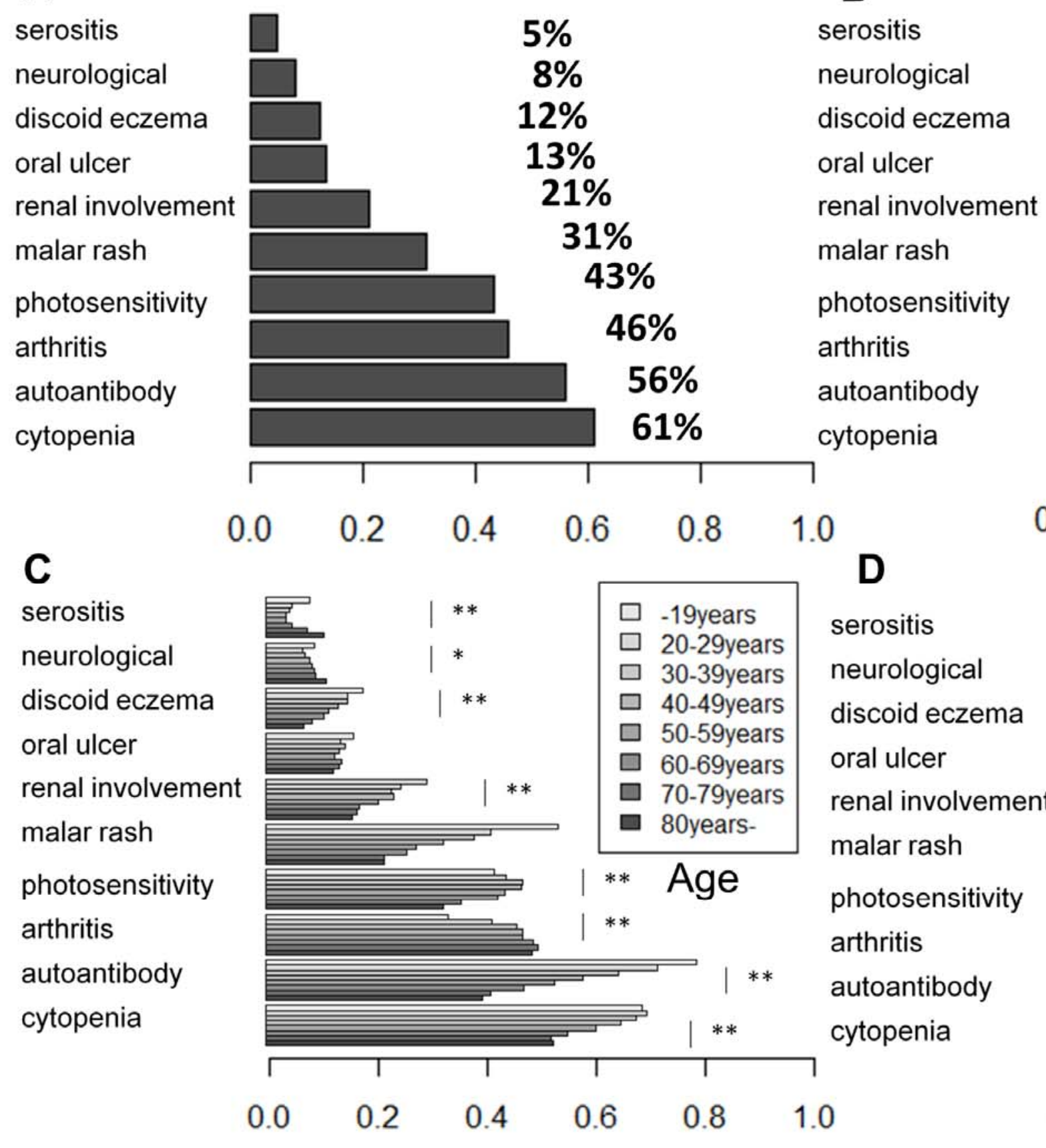

\section{B}

serositis

neurological

口 |**

$\square$
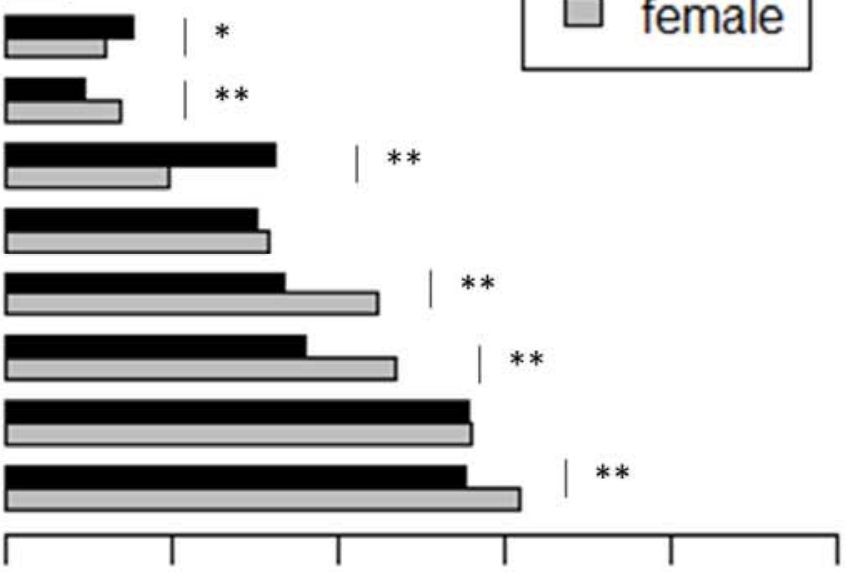

0.0

0.4

0.6

$0.8 \quad 1.0$

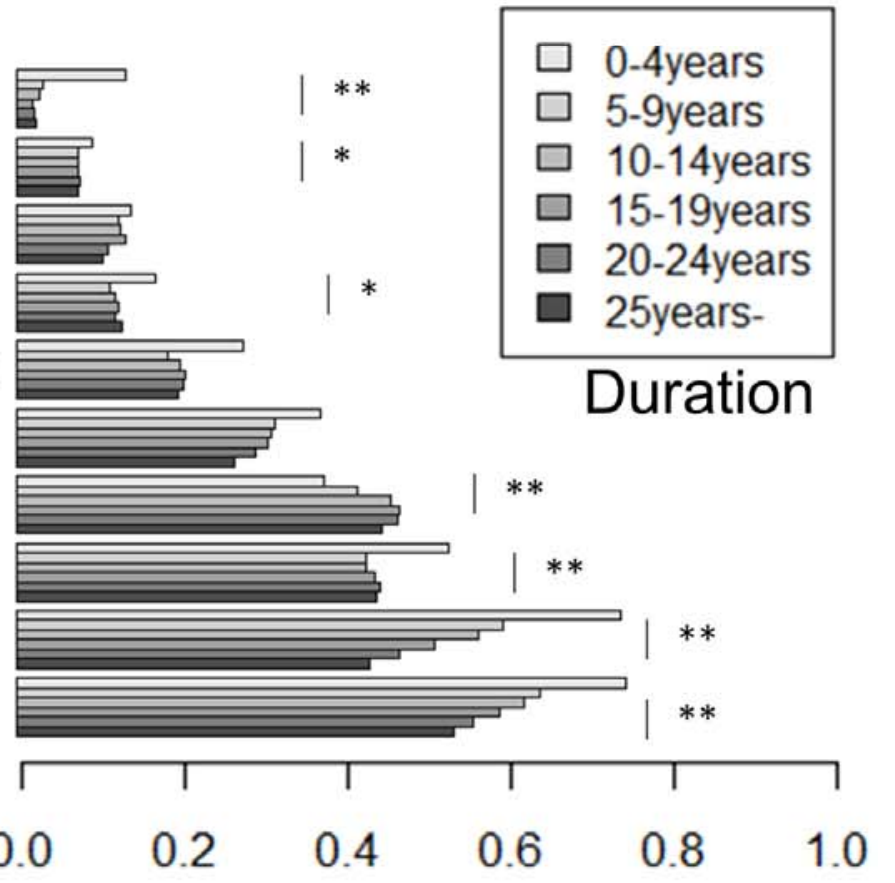

Figure 2 


\section{A}

serositis

neurological

discoid eczema

oral ulcer

renal involvement

malar rash

photosensitivity

arthritis

autoantibody

cytopenia

C

\section{serositis}

neurological

discoid eczema

oral ulcer

renal involvement

malar rash

photosensitivity

arthritis

autoantibody

cytopenia

\section{B}

serositis

neurological

discoid eczema

oral ulcer

renal involvement

malar rash

photosensitivity

arthritis

$37 \%$

$65 \%$

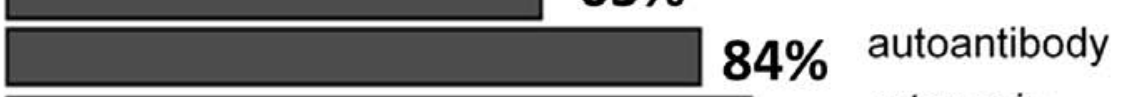

$90 \%$ cytopenia

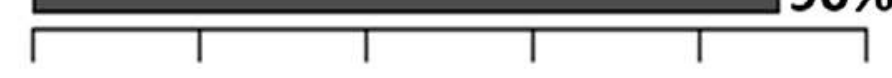

$\begin{array}{llllll}0.0 & 0.2 & 0.4 & 0.6 & 0.8 & 1.0\end{array}$

$0.0 \quad 0.2$

$\square$-19years

ㄴ 20-29years

ㅁ 30-39years

$\square$ 40-49years

50-59years

ㅁ 60-69years

ㅁ 70-79years

- 80years-

Age

\section{政}

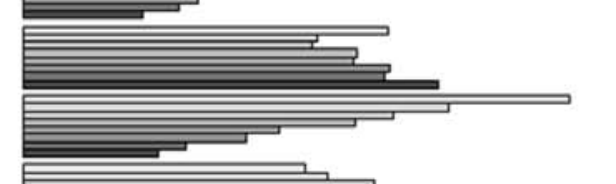

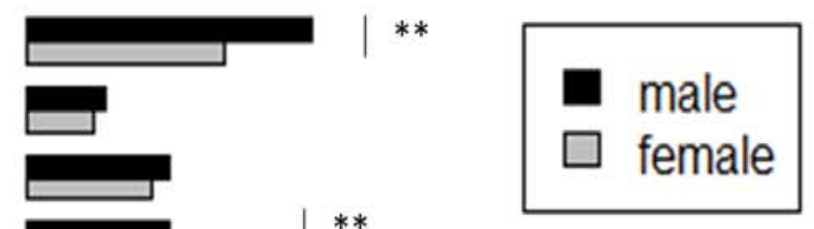
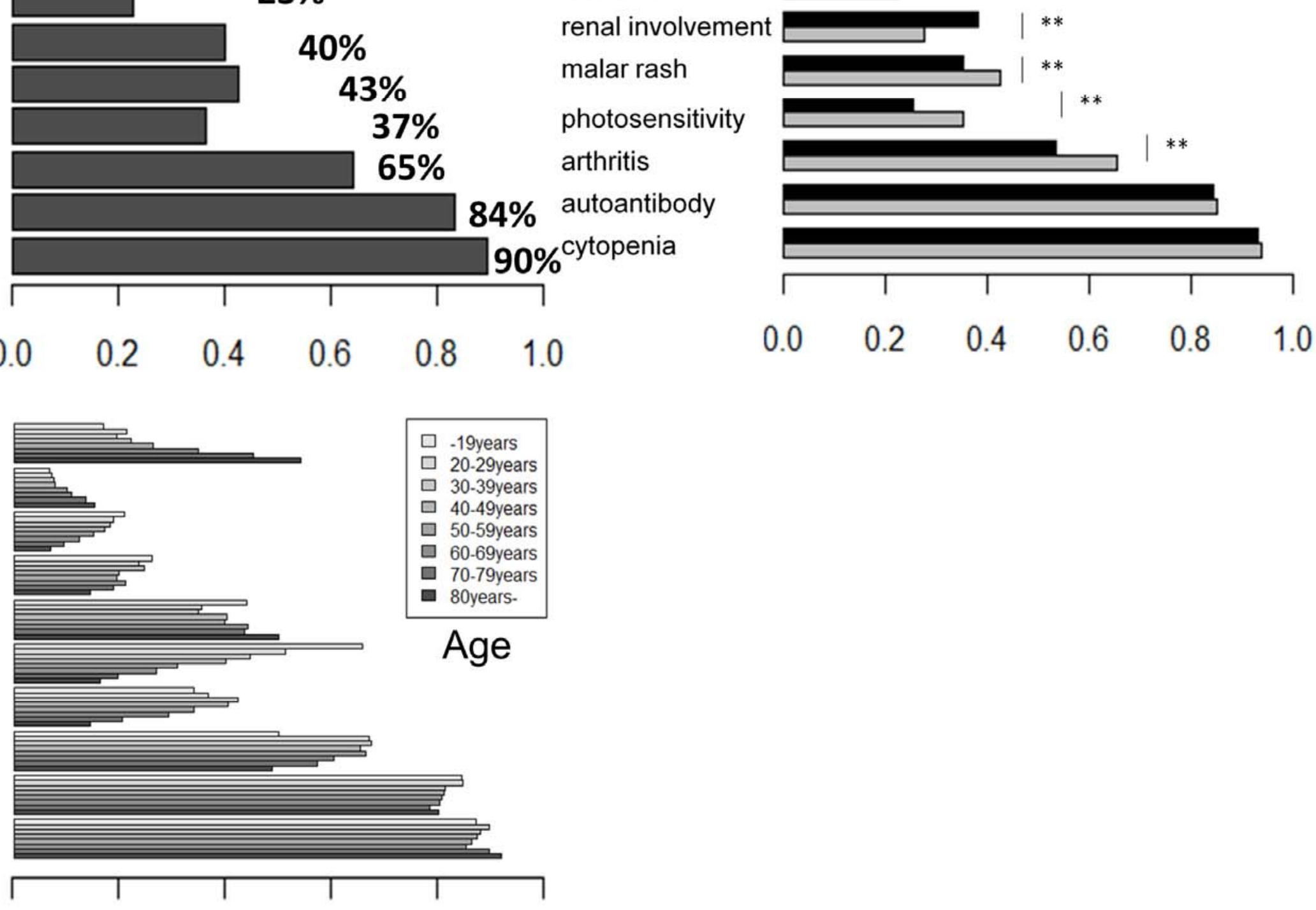

$\begin{array}{llllll}0.0 & 0.2 & 0.4 & 0.6 & 0.8 & 1.0\end{array}$

Figure 3 
A

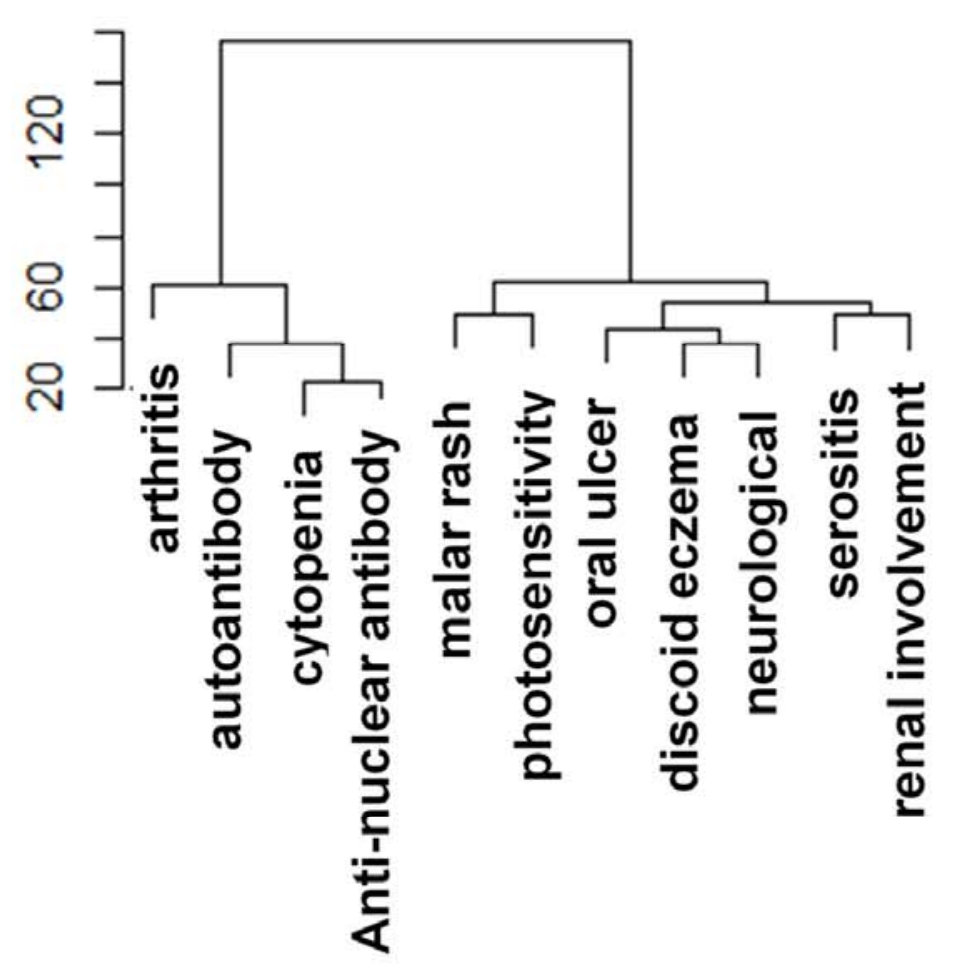

C

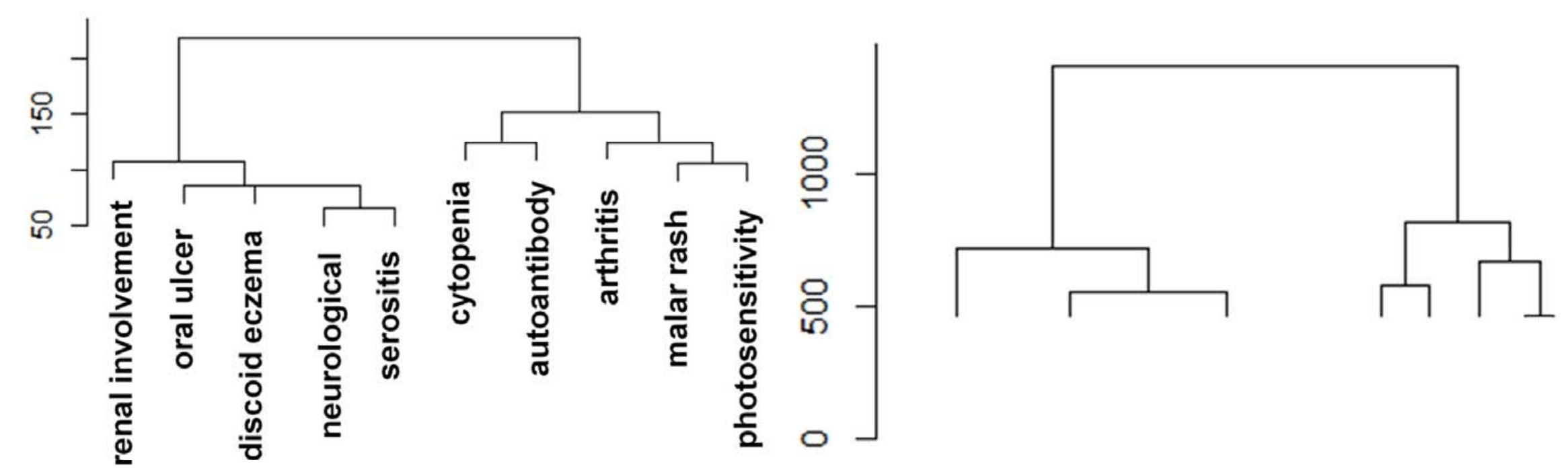

B

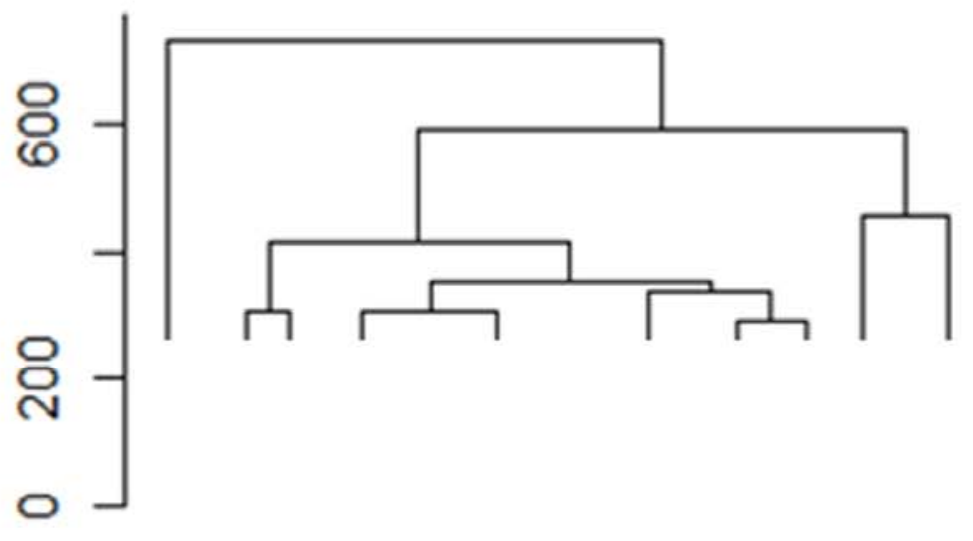

Figure 4 


\section{Supplementary Notes.}

To further assess the signs and clinical markers of SLE, we performed the detailed analyses outlined below.

Association studies to analyze the effects of age, sex, and disease duration on sign frequency were performed in the all SLE group. The resultant frequency data are shown in Supplementary Table 2. The association studies revealed that disease duration had a strong influence on sign frequency except for that of anti-phospholipid (APS) antibodies (Supplementary Table 3 and Supplementary Figure 3).

When we analyzed the detailed signs of SLE in the novel SLE group, we found that lymphopenia was the most common sign (Supplementary Table 2). More than half of the patients demonstrated anti-SS-A antibody positivity, leukopenia, and arthritis (Supplementary Table 2). When we analyzed the associations of age and sex with the detailed signs of SLE, we found that anti-SS-A antibody positivity, anti-SS-B antibody positivity, anti-U1RNP antibody positivity, Raynaud's phenomenon, leukopenia, and alopecia are frequently observed in female SLE patients, whereas pleuritis, interstitial pneumonia, thrombocytopenia, psychiatric signs, and pulmonary hemorrhaging are more frequently observed in male patients (Supplementary Figure 4 and Supplementary Table 4).

Next, we analyzed the prevalence of severe complications in patients with SLE, including infection, compression fractures of bone, gastric ulcers, bone necrosis, myocardial infarction, and cerebral infarction (Supplementary Table 7). We also analyzed the correlations between these complications and age, sex, and disease duration using multiple logistic regression analysis. As a result, we found that the contributions of age, sex, and disease duration to the development of severe complications differed greatly among the complications (Supplementary Figure 6). We found that bone necrosis is most likely to occur in young patients, while bone fractures tend to occur in older patients. We also analyzed whether complications are associated with particular clusters of patients in the all SLE group using ANOVA. Differences among the clusters were found for all complications, except bone necrosis and myocardial infarction (Supplementary Table 7). 
Supplementary Figure 1. Effects of sex, age, and disease duration on the major signs and markers of SLE in the all SLE group

Results of multiple logistic regression analysis of the annual frequencies of the 10 major signs of SLE in the all SLE group are shown for A) sex, B) age, C) disease duration, D) age in males and females, E) and disease duration in males and females. The vertical axes indicate odds ratios, and the lines indicate 95\% confidence intervals. Odds ratio are indicated for subjects of 10 years for age with a disease duration of five years. The blue and red lines indicate males and females, respectively.

Supplementary Figure 2. Detailed signs of SLE in the all SLE group Annual distributions of the detailed signs of SLE in the all SLE group according to A) sex, B) age, and C) disease duration. Results of multiple logistic regression analysis of the signs are shown for D) sex, E) age, F) disease duration, G) age in males and females, $\mathrm{H}$ ) and disease duration in males and females. The vertical axes indicate odds ratios, and the lines indicate 95\% confidence intervals. Odds ratios are shown for individuals of 10 years for age with a disease duration of five years. The blue and red lines indicate males and females, respectively. ${ }^{*}$ p-value $<10^{-5}$, **p-value $<10^{-10}$

Supplementary Figure 3. Effects of sex and age on signs and markers of SLE in the novel SLE group

Results of multiple logistic regression analysis of the 10 major signs of SLE are shown for A) sex and B) age. The results for the all SLE group are shown in deep red. C) Effects of age in males and females according to single logistic regression analysis. D) Distributions of the detailed signs according to sex. Multiple logistic regression analysis of the detailed signs according to E) sex and F) age. The results for the all SLE group are shown in deep red, if available. G) Effects of age on the frequencies of the detailed signs in males and females.

Detailed signs that displayed frequencies of greater than $5 \%$ are indicated.

${ }^{*}$ p-value $<10^{-5}$, ** p-value $<10^{-10}$

Supplementary Figure 4. Heat map of SLE patients and the 11 items for SLE in the novel SLE group

Supplementary Figure 5. Annual distribution of complications in the all SLE group A) Incidences of complications in the all SLE group. Incidences of complications according to sex (B), age (C), and disease duration (D). 
${ }^{*} \mathrm{p}$-value $<10^{-5}, * * \mathrm{p}$-value $<10^{-10}$

Supplementary Figure 6. Effects of APS antibody-related signs on cerebral and myocardial infarction.

A) Dose-dependent increase in the risk of cerebral infarction associated with APS autoantibodies.

B) Dose-dependent increase in the risk of acute myocardial infarction associated with APS autoantibodies.

Age-standardized incidences of males and females for C) cerebral infarction and D) myocardial infarction.

${ }^{*}$ p-value $<10^{-5}$, **p-value $<10^{-10}$ 
Supplementary Table 1.Clinical information collected in the novel and follow-up registries and converted into text files.

\begin{tabular}{|c|c|c|}
\hline & Novel & Follow-up \\
\hline Year of application & o & o \\
\hline Novel or Follow-up registry & ० & $\circ$ \\
\hline Sex & ○ & $\circ$ \\
\hline Year of Birth & $\circ$ & $\circ$ \\
\hline Current prefectural address & ० & $\circ$ \\
\hline Prefecture at birth & $\circ$ & $\circ$ \\
\hline Current Age & ० & ○ \\
\hline Prefecture at onset & $\circ$ & $\circ$ \\
\hline Time of onset (yyyy/mm) & $\circ$ & $\circ$ \\
\hline Age at onset & $\circ$ & $\circ$ \\
\hline Time of first visit & ○ & ○ \\
\hline Information of insurance & $\circ$ & $\circ$ \\
\hline Information of disability & ○ & ○ \\
\hline qualify of disability, grade & $\circ$ & $\circ$ \\
\hline time of qualification & & ○ \\
\hline Social activity status & ○ & $\circ$ \\
\hline unspecified family history & ○ & \\
\hline information of family affected & ○ & \\
\hline Frequency of hospital visit & ० & $\circ$ \\
\hline
\end{tabular}

Detailed items for cytopenia

$\begin{array}{ccc}\text { Hemolytic anemia } & \circ & \circ \\ \text { Leukopenia } & \circ & \circ \\ \text { Lymphopenia } & \circ & \circ \\ \text { Thrombocytopenia } & \circ & \circ\end{array}$

Detailed items for autoantibodies

Anti-nuclear antibody

Anti-dsDNA antibody

Anti-sm antibody

Anti-RNP antibody $\quad \circ$

Anti-SSA antibody $\quad$

Anti-SSB antibody 0

Detailed items for anti-phospholipid syndrome 
Anti-cardiolipin antibody

O

Lupus anticoagulant

Biological false-positive for syphilis

Renal involvement

Detailed items related with renal dysfunction

Rapid progressive glomerulonephritis

Acute renal failure

Chronic renal failure

Nephrosis

Renal biopsy WHO class

Protein urea

microscopic/macroscopic hematourea

cast

serum creatinine

CH50 level

C3 level

C4 level

Neurological signs
Detailed items related to psychoneurological signs

Seizure $\quad \circ$

Psychosis 0

Organic brain syndrome $\quad$

Cranial nerve sign $\quad \circ$

Multiple mononeuritis 0

Disturbance of consciousness 0

Cerebral vascular disorder $\quad$ o

Spinal cord lesion $\quad \circ$

Aseptic meningitis $\quad$

Serositis

Detailed items related to cardiopulmonary signs

Pleuritis

Pericarditis

Interstitial pneumoniae

Pulmonary hypertension $\quad$ ○

Pulmonary thrombosis 0

Pulmonary hemorrhage $\quad$ o 
Detailed items related to skin signs

Photosensitivity

Malar rash

Oral ulcer

Discoid eczema

Alopecia

Raynaud's phenomenon

Detailed items related to musculoskeletal signs

$\begin{array}{ll}\text { Arthritis } & \circ \\ \text { Myalgia } & \circ\end{array}$

Muscle weakness

Differential diagnosis:Whether or not the patients' symptoms and signs are explained by:

Other connective tissue diseases 0

Drug-induced lupus $\quad \circ$

Infection

Hematopoietic Disorders $\quad \circ$

Malignancies

Treatment:Usage, period and effect of

$\begin{array}{ccc}\text { Corticosteroid } & \circ & \circ \\ \text { NSAIDs } & \circ & \circ \\ \text { steroid pulse } & \circ & \circ \\ \text { immunosuppressant } & \circ & \circ \\ \text { Plasma exchange } & \circ & \circ \\ \text { Plasma apheresis } & \circ & \circ \\ \text { Others } & \circ & \circ\end{array}$

Complications:

$\begin{array}{ccc}\text { Myocardial infarction } & \circ & \circ \\ \text { Cerebral infarction } & \circ & \circ \\ \text { Peptic ulcer } & \circ & \circ \\ \text { Bone fracture } & \circ & \circ \\ \text { Bone necrosis } & \circ & \circ \\ \text { Infection } & \circ & \circ \\ \text { Diabetes mellitus } & \circ & \circ\end{array}$




\begin{tabular}{ccc} 
hypertension & 0 & 0 \\
malignancy & $\circ$ & 0 \\
DIC & 0 & $\circ$ \\
others & $\circ$ & $\circ$ \\
\hline
\end{tabular}

Supplementary Table 2. Frequency of SLE signs and markers in the SLE groups

Novel group

Number of patients Positivity rate Number of patients

Positivity

rate

Major 11 signs of SLE

Anti-nuclear antibody

Cytopenia

Autoantibodies

Arthritis

Photosensitivity

Malar rash

Renal involvement

Oral ulcer

Discoid eczema

Neurological signs

Serositis

Detailed items for cytopenia

Hemolytic anemia

Leukopenia

Lymphopenia

Thrombocytopenia

Detailed items for autoantibodies

Anti-dsDNA antibody

Anti-sm antibody

Anti-RNP antibody

Anti-SSA antibody

Anti-SSB antibody

Detailed items for anti-phospholipid syndrome

Anti-cardiolipin antibody

Lupus anticoagulant
8970

9275

9205

9254

9255

9313

8736

9235

9283

9295

9241

7667

9259

8861

9228

7901

7912

7178

7387

6582

6603

5259
$98.4 \% \quad$ NA

$90.0 \%$

83.9\%

$64.7 \%$

$36.6 \%$

$43.0 \%$

$40.4 \%$

$22.9 \%$

$17.0 \%$

$8.8 \%$

$25.3 \%$

$12.8 \%$

$56.9 \%$

$86.8 \%$

$20.4 \%$

$76.9 \%$

$36.4 \%$

$42.0 \%$

NA

$55.7 \%$

$18.3 \%$

NA

NA

$28.0 \%$

$22.2 \%$

\section{NA}

$41761 \quad 61.0 \%$

$4016455.8 \%$

$41600 \quad 45.8 \%$

$4121143.4 \%$

$41766 \quad 31.3 \%$

$40967 \quad 20.9 \%$

$4159313.4 \%$

$4165912.4 \%$

41009 8.0\%

$41312 \quad 4.6 \%$
$41076 \quad 3.5 \%$

$41592 \quad 26.7 \%$

$4116356.6 \%$

$414759.6 \%$
$39323 \quad 46.2 \%$

$2906618.5 \%$

NA

NA

NA 
Biological false-positive for syphilis

Detailed items related with renal dysfunction

Rapid progressive glomerulonephritis

Acute renal failure

Chronic renal failure

Nephrosis
6237

9099

9110

9105

9111

9287

9256

Cranial nerve sign

Multiple mononeuritis

Disturbance of consciousness

Cerebral vascular disorder

Spinal cord lesion

Aseptic meningitis

9243

9247

9200

9196

9188

9187

9176
Organic brain syndrome

9217

9186

9181

9074

9143

9149

Pulmonary hemorrhage

Detailed items related to skin signs

$$
\text { Alopecia }
$$

Raynaud's phenomenon

Detailed items related to musculoskeletal signs

$$
\text { Myalgia }
$$

Muscle weakness

9189

9162

9143

9110
$11.1 \%$

$19739 \quad 6.0 \%$

$8.1 \% \quad \mathrm{NA}$

NA

$6.3 \% \quad \mathrm{NA}$

NA

$4.4 \% \quad$ NA

NA

$16.1 \% \quad \mathrm{NA}$

NA

$2.2 \% \quad N A$

NA

$7.5 \% \quad$ NA

NA

$1.9 \%$

NA

NA

2.3\% NA

NA

$4.7 \% \quad$ NA

NA

$4.5 \%$

NA

NA

$4.5 \%$

NA

NA

$0.5 \%$

NA

NA

$1.6 \%$

NA

NA

NA

NA

NA

NA

NA

NA

$24.9 \%$

NA

NA

$26.9 \%$

NA

NA

$30.8 \%$

NA

NA

NA

NA

Supplementary Table 3. Multiple logistic regression analysis of the effects of sex, age, and disease duration on the frequencies of SLE signs and markers in the all SLE group

\begin{tabular}{ccccccc}
\hline & \multicolumn{2}{c}{ Sex } & \multicolumn{2}{c}{ Age } & \multicolumn{2}{c}{ Duration } \\
& $\mathrm{p}$ & $\mathrm{OR}$ & $\mathrm{p}$ & $\mathrm{OR}$ & $\mathrm{p}$ & $\mathrm{OR}$ \\
\hline Cytopenia & $9.4 \times 10^{-20}$ & $1.44(1.33-1.55)$ & $1.5 \times 10^{-22}$ & $0.92(0.91-0.94)$ & $9.6 \times 10^{-87}$ & $0.88(0.87-0.89)$
\end{tabular}




\begin{tabular}{|c|c|c|c|c|c|c|}
\hline Autoantibodies & 0.032 & 1.09 (1.01-1.18) & $1.9 \times 10^{-101}$ & $0.83(0.82-0.85)$ & $4.7 \times 10^{-122}$ & $0.85(0.84-0.86)$ \\
\hline Arthritis & $3.9 \times 10^{-41}$ & 1.73 (1.6-1.87) & $3.4 \times 10^{-40}$ & $1.12(1.10-1.13)$ & $3.1 \times 10^{-40}$ & $0.92(0.91-0.93)$ \\
\hline Photosensitivity & $6.4 \times 10^{-23}$ & $1.50(1.38-1.63)$ & $2.7 \times 10^{-25}$ & $0.92(0.90-0.93)$ & $2.3 \times 10^{-26}$ & $1.07(1.06-1.09)$ \\
\hline Malar rash & 0.22 & $1.05(0.97-1.15)$ & $2.8 \times 10^{-107}$ & $0.82(0.80-0.83)$ & 0.036 & $0.99(0.97-1.00)$ \\
\hline Renal involvement & $9.1 \times 10^{-57}$ & $0.51(0.47-0.55)$ & $2.6 \times 10^{-26}$ & $0.90(0.88-0.92)$ & 0.0057 & $0.98(0.96-0.99)$ \\
\hline Oral ulcer & $1.4 \times 10^{-10}$ & $1.51(1.33-1.71)$ & 0.91 & $1.00(0.98-1.02)$ & $2.4 \times 10^{-8}$ & $0.95(0.93-0.97)$ \\
\hline Discoid eczema & $5.7 \times 10^{-7}$ & $0.76(0.68-0.85)$ & $3.8 \times 10^{-21}$ & $0.89(0.87-0.91)$ & 0.77 & $1.00(0.98-1.02)$ \\
\hline Neurological signs & 0.79 & $1.02(0.89-1.17)$ & $2.1 \times 10^{-9}$ & 1.09 (1.06-1.12) & $1.7 \times 10^{-6}$ & $0.94(0.92-0.97)$ \\
\hline Serositis & 0.00014 & $0.75(0.65-0.87)$ & $6.4 \times 10^{-37}$ & 1.23 (1.19-1.27) & $1.8 \times 10^{-137}$ & $0.60(0.57-0.62)$ \\
\hline Hemolytic anemia & 0.26 & $0.90(0.75-1.08)$ & 0.85 & $1.00(0.97-1.04)$ & $3.3 \times 10^{-38}$ & $0.77(0.74-0.80)$ \\
\hline Leukocytopenia & $5.8 \times 10^{-19}$ & 1.51 (1.38-1.65) & $7.8 \times 10^{-13}$ & $0.94(0.92-0.95)$ & $1.1 \times 10^{-104}$ & $0.84(0.83-0.86)$ \\
\hline Lymphopenia & $3.6 \times 10^{-14}$ & $1.35(1.25-1.46)$ & $1.9 \times 10^{-32}$ & $0.90(0.89-0.92)$ & $3.3 \times 10^{-86}$ & $0.88(0.87-0.89)$ \\
\hline hrombocytopenia & 0.76 & $0.98(0.87-1.11)$ & $1.2 \times 10^{-5}$ & 1.06 (1.03-1.09) & $5.1 \times 10^{-26}$ & $0.89(0.87-0.91)$ \\
\hline $\begin{array}{c}\text { Anti-dsDNA } \\
\text { antibody }\end{array}$ & 0.00027 & $1.16(1.07-1.26)$ & $7.2 \times 10^{-97}$ & $0.83(0.82-0.85)$ & $9.4 \times 10^{-118}$ & $0.85(0.84-0.86)$ \\
\hline Anti-sm antibody & 0.29 & $1.06(0.95-1.19)$ & $1.3 \times 10^{-42}$ & $0.85(0.83-0.87)$ & $4.1 \times 10^{-76}$ & $0.81(0.79-0.83)$ \\
\hline $\begin{array}{l}\text { Anti-cardiolipin } \\
\text { antibody }\end{array}$ & 0.0014 & $0.82(0.73-0.93)$ & $2.6 \times 10^{-6}$ & $0.94(0.91-0.96)$ & 0.33 & $1.01(0.99-1.03)$ \\
\hline $\begin{array}{l}\text { upus anticoagulant } \\
\text { Biological }\end{array}$ & 0.11 & $0.88(0.76-1.03)$ & $2.3 \times 10^{-6}$ & $0.92(0.89-0.95)$ & 0.38 & $0.99(0.96-1.01)$ \\
\hline $\begin{array}{l}\text { false-positive for } \\
\text { syphilis }\end{array}$ & 0.51 & $1.08(0.86-1.36)$ & $5.8 \times 10^{-7}$ & $0.88(0.84-0.93)$ & 0.00059 & $0.93(0.89-0.97)$ \\
\hline
\end{tabular}


Supplementary Table 4. Effects of age and sex on the frequency of SLE signs and markers in the novel SLE group

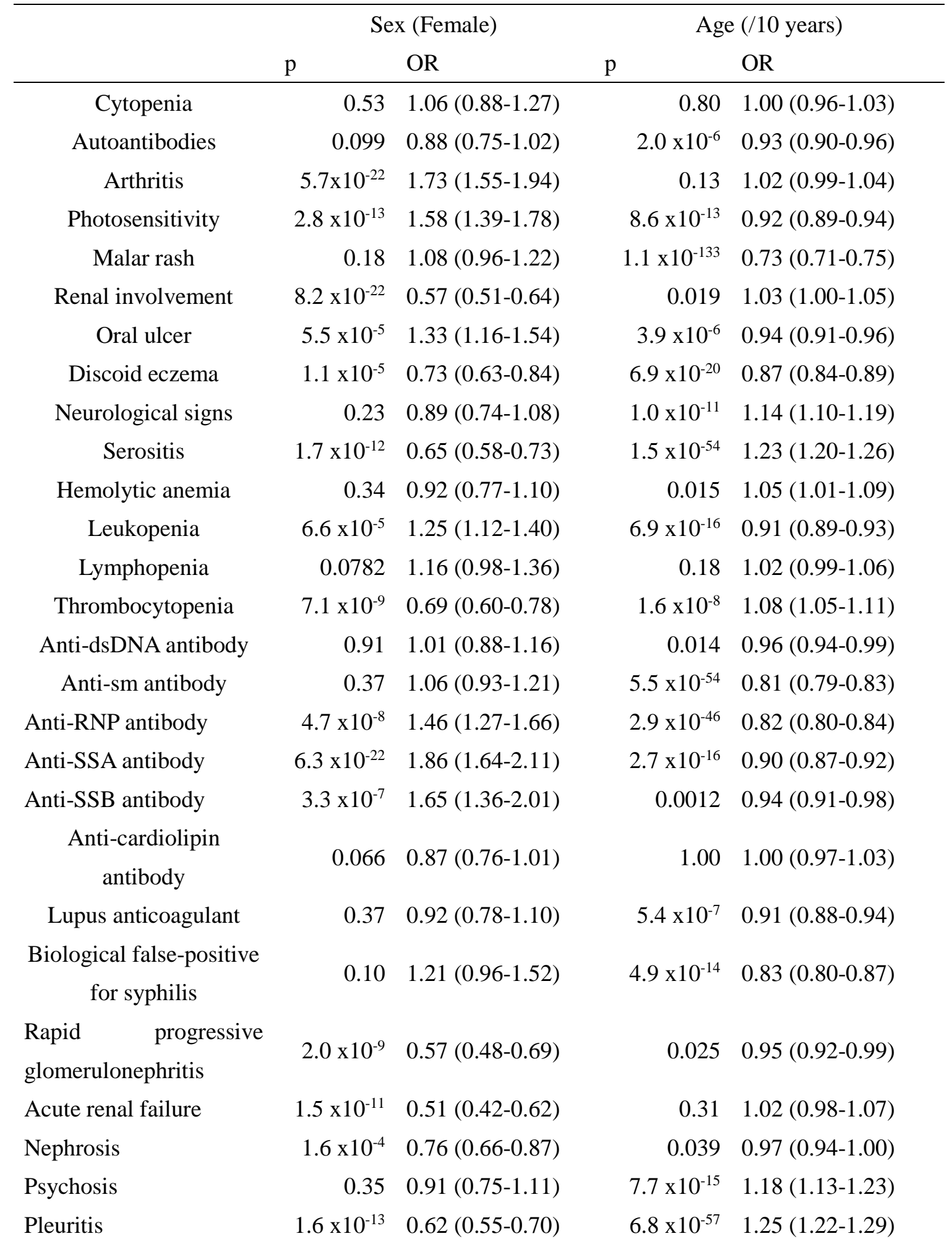




$\begin{array}{lrrrr}\text { Pericarditis } & 0.14 & 0.89(0.77-1.04) & 2.3 \times 10^{-17} & 1.15(1.11-1.18) \\ \text { Interstitial pneumonia } & 4.1 \times 10^{-5} & 0.68(0.57-0.82) & 6.7 \times 10^{-62} & 1.44(1.38-1.50) \\ \text { Alopecia } & 2.0 \times 10^{-9} & 1.53(1.33-1.76) & 0.014 & 0.97(0.94-0.99) \\ \text { Raynaud's phenomenon } & 5.8 \times 10^{-25} & 2.13(1.85-2.46) & 6.0 \times 10^{-5} & 1.05(1.03-1.08) \\ \text { Myalgia } & 0.33 & 1.06(0.94-1.20) & 0.0068 & 1.03(1.01-1.06) \\ \text { Muscle weakness } & 0.87 & 0.99(0.86-1.13) & 2.8 \times 10^{-97} & 1.36(1.32-1.40)\end{array}$


Supplementary Table 5. Distribution of signs and markers in 10 clusters of SLE patients in the novel SLE group

Number

Discoid Oral Malar Photo-

Arthritis

eczema ulcer rash sensitivity

Autoantibodies Cytopenia ANA Renal Neurological Serositis

of patients (freq.) 1490 (22.4\%) 703 (10.6\%) 840 (12.7\%) 607 (9.1\%) 658 (9.9\%) 378 (5.7\%) 429 (6.5\%) 650 (9.8\%) 263 (4\%) 619 (9.3\%) 
Supplementary Table 6. Distribution of signs and markers in eight clusters of patients in the all SLE group

\begin{tabular}{|c|c|c|c|c|c|c|c|c|c|c|c|}
\hline & Arthritis & $\begin{array}{l}\text { Discoid } \\
\text { eczema }\end{array}$ & $\begin{array}{l}\text { Oral } \\
\text { ulcer }\end{array}$ & $\begin{array}{c}\text { Malar } \\
\text { rash }\end{array}$ & $\begin{array}{c}\text { Photo } \\
\text { sensitivity }\end{array}$ & Autoantibodies & Cytopenia & Renal & Neurological & Serositis & $\begin{array}{c}\text { Number } \\
\text { of } \\
\text { patients } \\
\text { (freq.) }\end{array}$ \\
\hline 1 & 0.57 & 0.2 & 0.55 & 0.36 & 0.5 & 0.65 & 0.61 & 0.19 & 0.4 & 0.26 & $\begin{array}{l}2129 \\
(21.3 \%)\end{array}$ \\
\hline 2 & 0 & 0 & 0 & 0 & 0 & 0 & 0 & 0 & 0 & 0 & $\begin{array}{l}687 \\
(6.9 \%)\end{array}$ \\
\hline 3 & 0.43 & 0.14 & 0.11 & 0.37 & 0.46 & 0.64 & 0.62 & 0.99 & 0.01 & 0.04 & $\begin{array}{l}1641 \\
(16.4 \%)\end{array}$ \\
\hline 4 & 0 & 0 & 0 & 0 & 0 & 1 & 0 & 0 & 0 & 0 & $\begin{array}{l}390 \\
(3.9 \%)\end{array}$ \\
\hline 5 & 0 & 0 & 0 & 0 & 0 & 1 & 1 & 0 & 0 & 0 & $\begin{array}{l}590 \\
(5.9 \%)\end{array}$ \\
\hline 6 & 0.49 & 0.21 & 0 & 0.55 & 0.78 & 0.54 & 0.62 & 0 & 0 & 0 & $\begin{array}{l}3151 \\
\text { (31.5\%) }\end{array}$ \\
\hline 7 & 0 & 0 & 0 & 0 & 0 & 0 & 1 & 0 & 0 & 0 & $\begin{array}{l}507 \\
(5.1 \%)\end{array}$ \\
\hline 8 & 1 & 0 & 0 & 0 & 0 & 0.53 & 0.61 & 0 & 0 & 0 & $\begin{array}{l}905 \\
(9.1 \%)\end{array}$ \\
\hline
\end{tabular}


Supplementary Table 7. Annual incidence of complications in the all SLE group

\begin{tabular}{|c|c|c|c|c|c|c|c|c|c|}
\hline \multirow[t]{2}{*}{ Complications } & \multirow{2}{*}{ Number } & \multirow{2}{*}{$\begin{array}{c}\text { Positivity } \\
\text { rate }\end{array}$} & \multicolumn{2}{|c|}{ Sex } & \multicolumn{2}{|c|}{ Age } & \multicolumn{2}{|c|}{ Duration } & \multirow{2}{*}{$\begin{array}{l}\text { ANOVA } \\
\text { p-value }\end{array}$} \\
\hline & & & $\mathrm{P}$ & OR & $\mathrm{p}$ & OR & $\mathrm{p}$ & OR & \\
\hline $\begin{array}{l}\text { Myocardial } \\
\text { infarction }\end{array}$ & 41488 & $0.70 \%$ & $2.1 \times 10^{-6}$ & $\begin{array}{c}0.43 \\
(0.25-0.55)\end{array}$ & $2.6 \times 10^{-23}$ & $\begin{array}{c}1.65 \\
(1.48-1.81)\end{array}$ & 0.066 & $\begin{array}{c}1.06 \\
(0.99-1.13)\end{array}$ & 0.0090 \\
\hline $\begin{array}{l}\text { Cerebral } \\
\text { infarction }\end{array}$ & 41449 & $2.40 \%$ & 0.047 & $\begin{array}{c}0.79 \\
(0.58-0.95)\end{array}$ & $1.4 \times 10^{-45}$ & $\begin{array}{c}1.49 \\
(1.4-1.56)\end{array}$ & 0.11 & $\begin{array}{c}1.03 \\
(0.99-1.07)\end{array}$ & $7.2 \times 10^{-18}$ \\
\hline Gastric ulcer & 41138 & $3.20 \%$ & 0.75 & $\begin{array}{c}0.96 \\
(0.73-1.16)\end{array}$ & $3.6 \times 10^{-27}$ & $\begin{array}{c}1.29 \\
(1.23-1.35)\end{array}$ & 0.00035 & $\begin{array}{c}1.06 \\
(1.03-1.10)\end{array}$ & $7.5 \times 10^{-12}$ \\
\hline $\begin{array}{l}\text { Bone } \\
\text { fracture }\end{array}$ & 41343 & $5.70 \%$ & $2.2 \times 10^{-7}$ & $\begin{array}{c}1.74 \\
(1.33-2.07)\end{array}$ & $1.7 \times 10^{-169}$ & $\begin{array}{c}1.77 \\
(1.69-1.84)\end{array}$ & $8.7 \times 10^{-13}$ & $\begin{array}{c}1.09 \\
(1.07-1.12)\end{array}$ & $4.4 \times 10^{-11}$ \\
\hline $\begin{array}{c}\text { Bone } \\
\text { necrosis }\end{array}$ & 41179 & $7.20 \%$ & 0.029 & $\begin{array}{c}0.84 \\
(0.71-0.96)\end{array}$ & $2.1 \times 10^{-19}$ & $\begin{array}{c}0.85 \\
(0.82-0.88)\end{array}$ & $\begin{array}{c}7.8 \\
\times 10^{-83}\end{array}$ & $\begin{array}{c}1.27 \\
(1.24-1.30)\end{array}$ & 0.81 \\
\hline Infection & 41475 & $13.00 \%$ & 0.57 & $\begin{array}{c}0.97 \\
(0.85-1.07)\end{array}$ & $5.2 \times 10^{-20}$ & $\begin{array}{c}1.12 \\
(1.09-1.14)\end{array}$ & 0.015 & $\begin{array}{c}1.02 \\
(1.00-1.04)\end{array}$ & $1.2 \times 10^{-7}$ \\
\hline
\end{tabular}


A

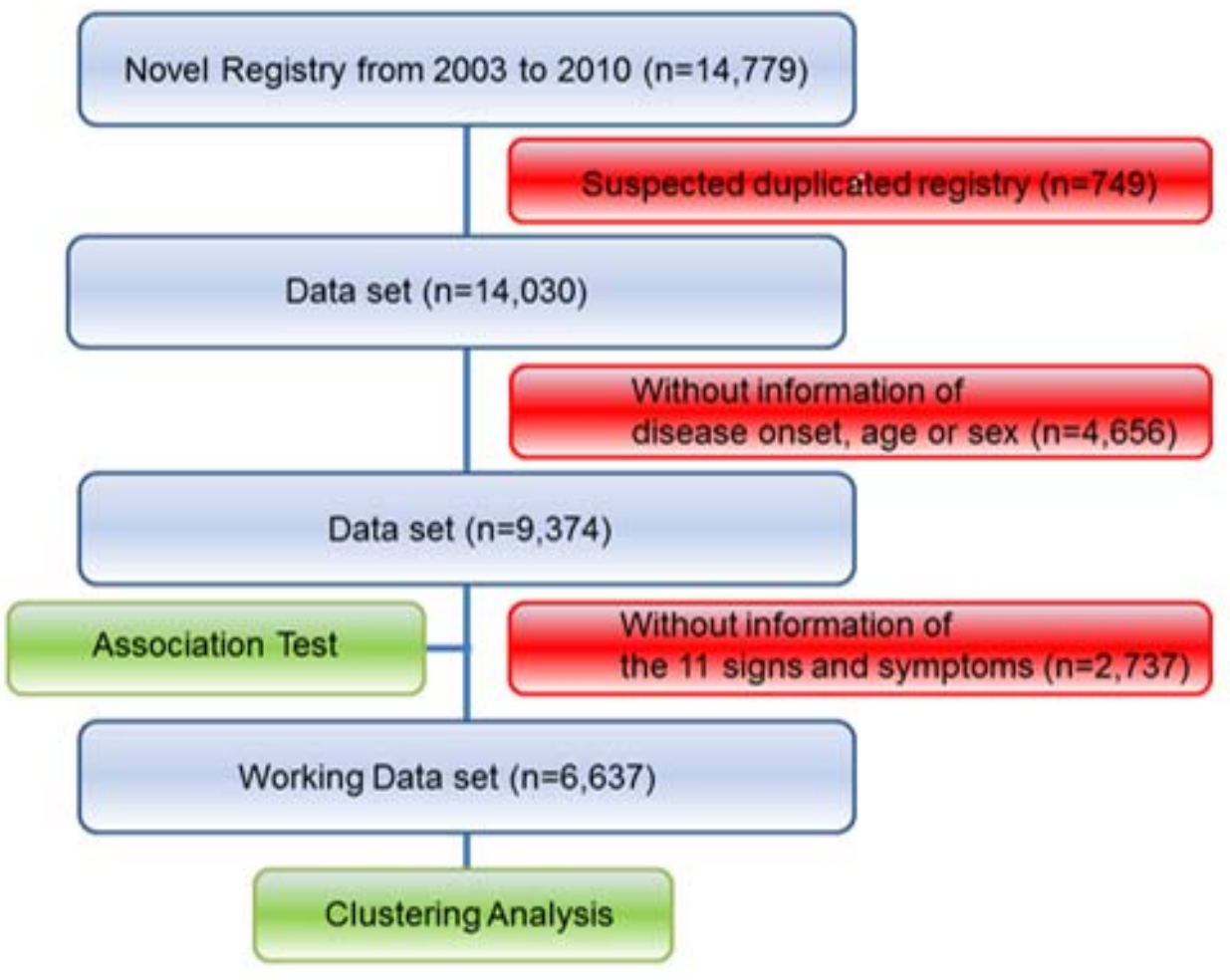

B

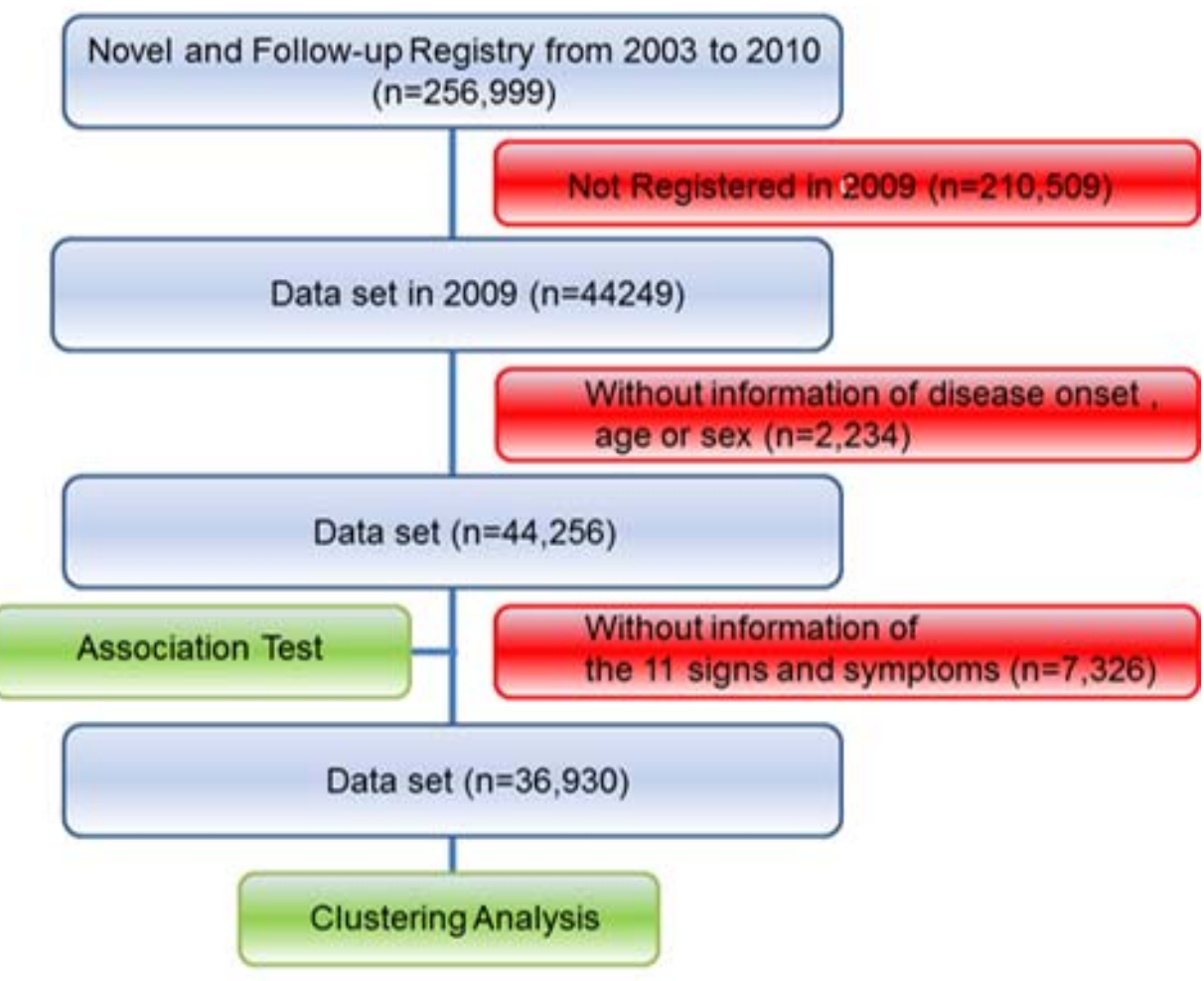


A

serisitis neurological discoid eczema oral ulcer renal involvement malar rash photosensitivity arthritis autoantibody cytopenia

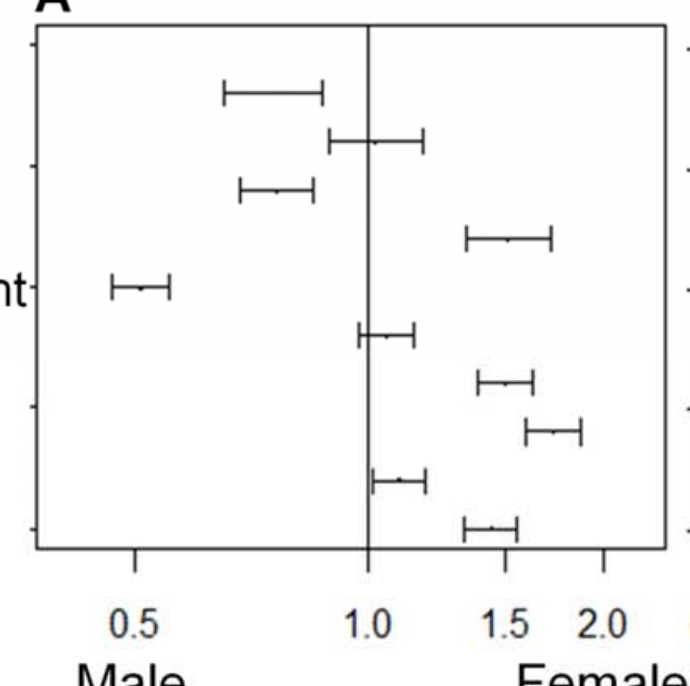

B

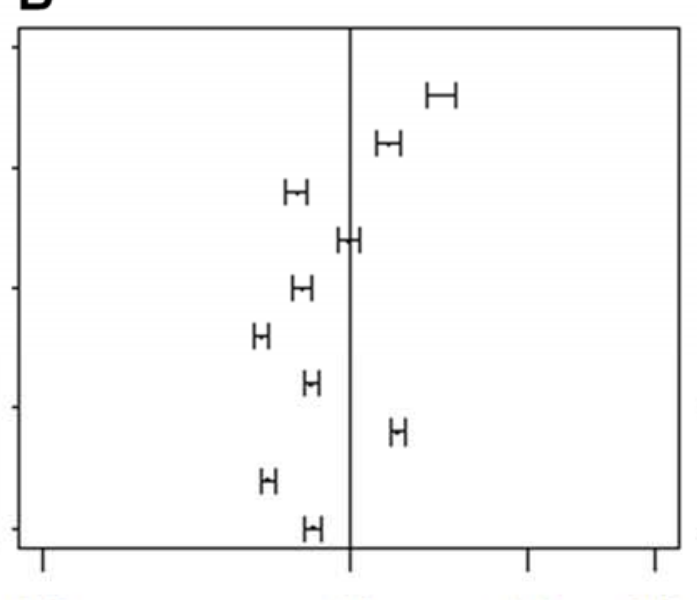

C

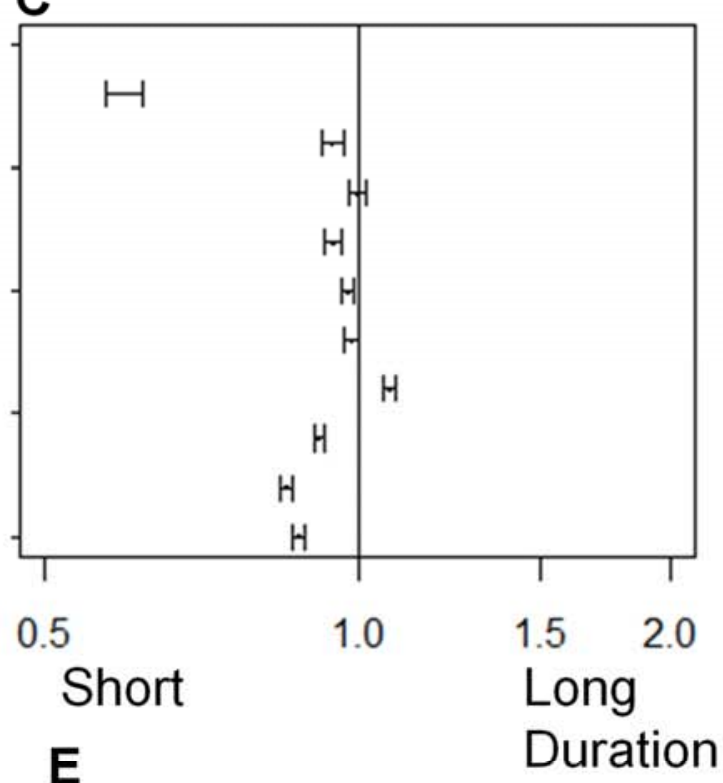

serisitis neurological discoid eczema oral ulcer renal involvement malar rash photosensitivity arthritis autoantibody cytopenia

Fema
ment

0.5

D

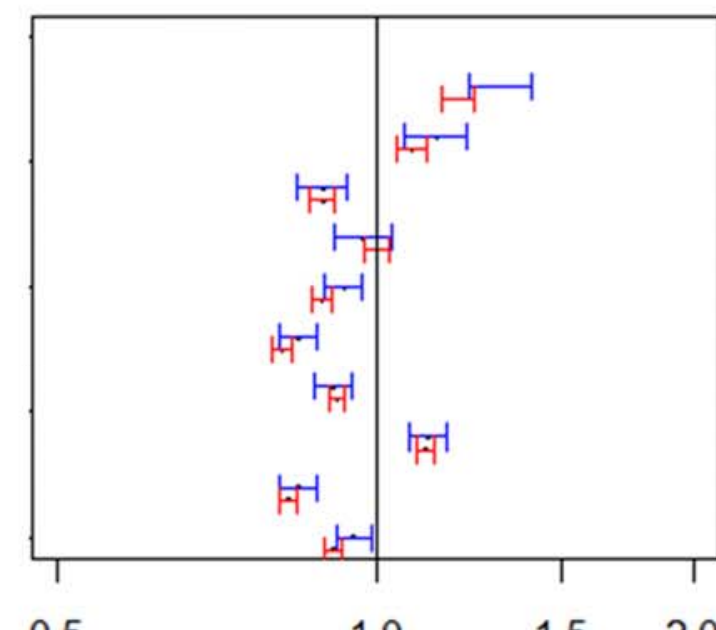

0.5 Young

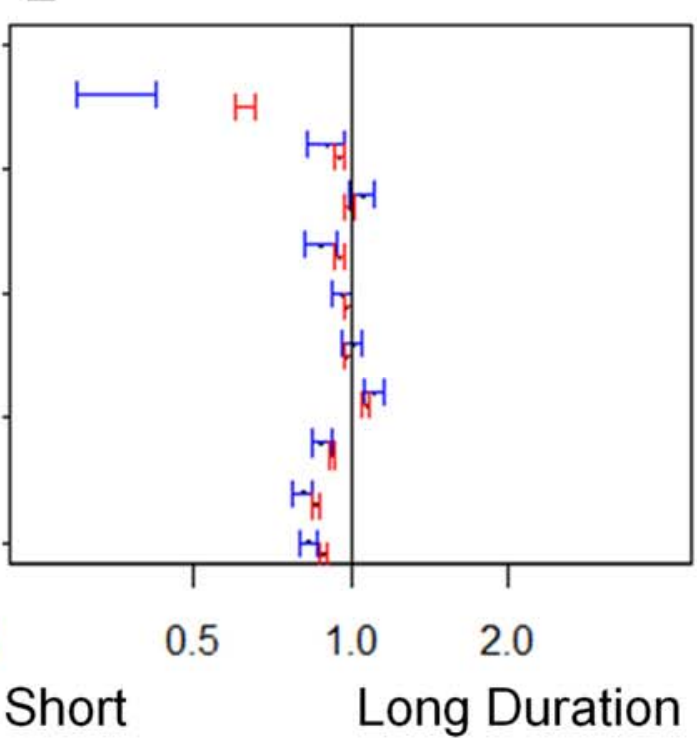




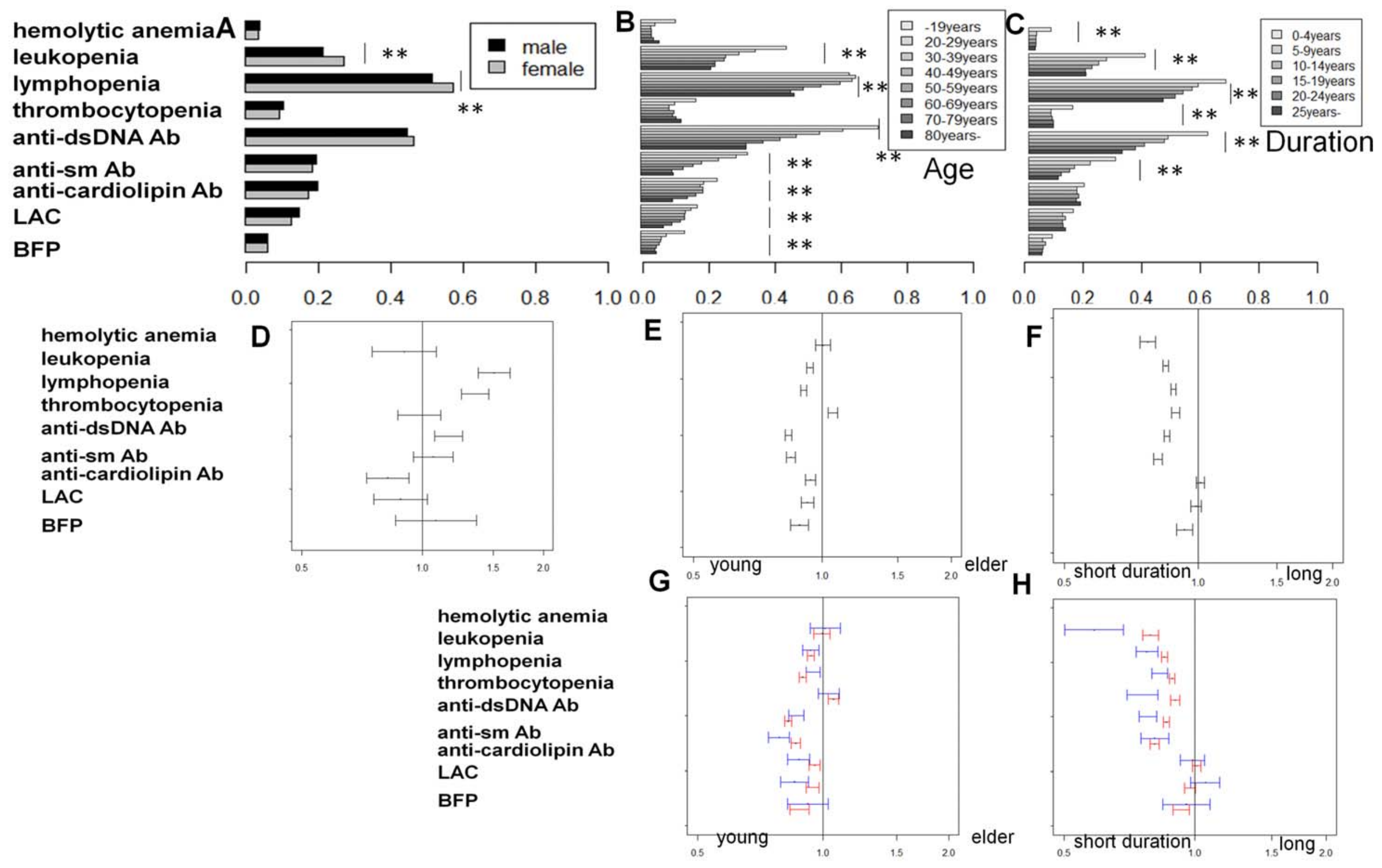

Supplementary Figure 3 

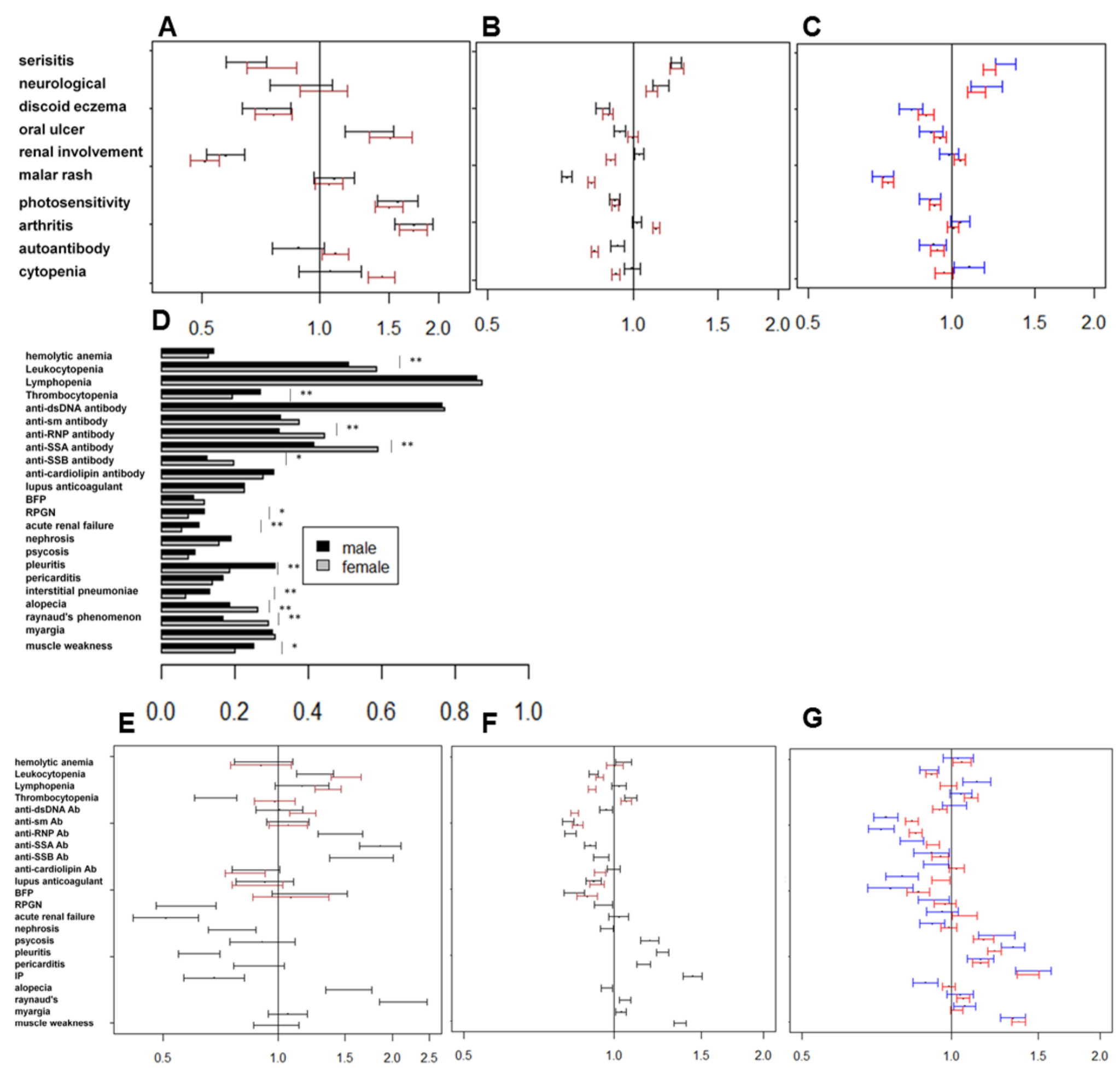

Supplementary Figure 4 


\section{Signs and markers}

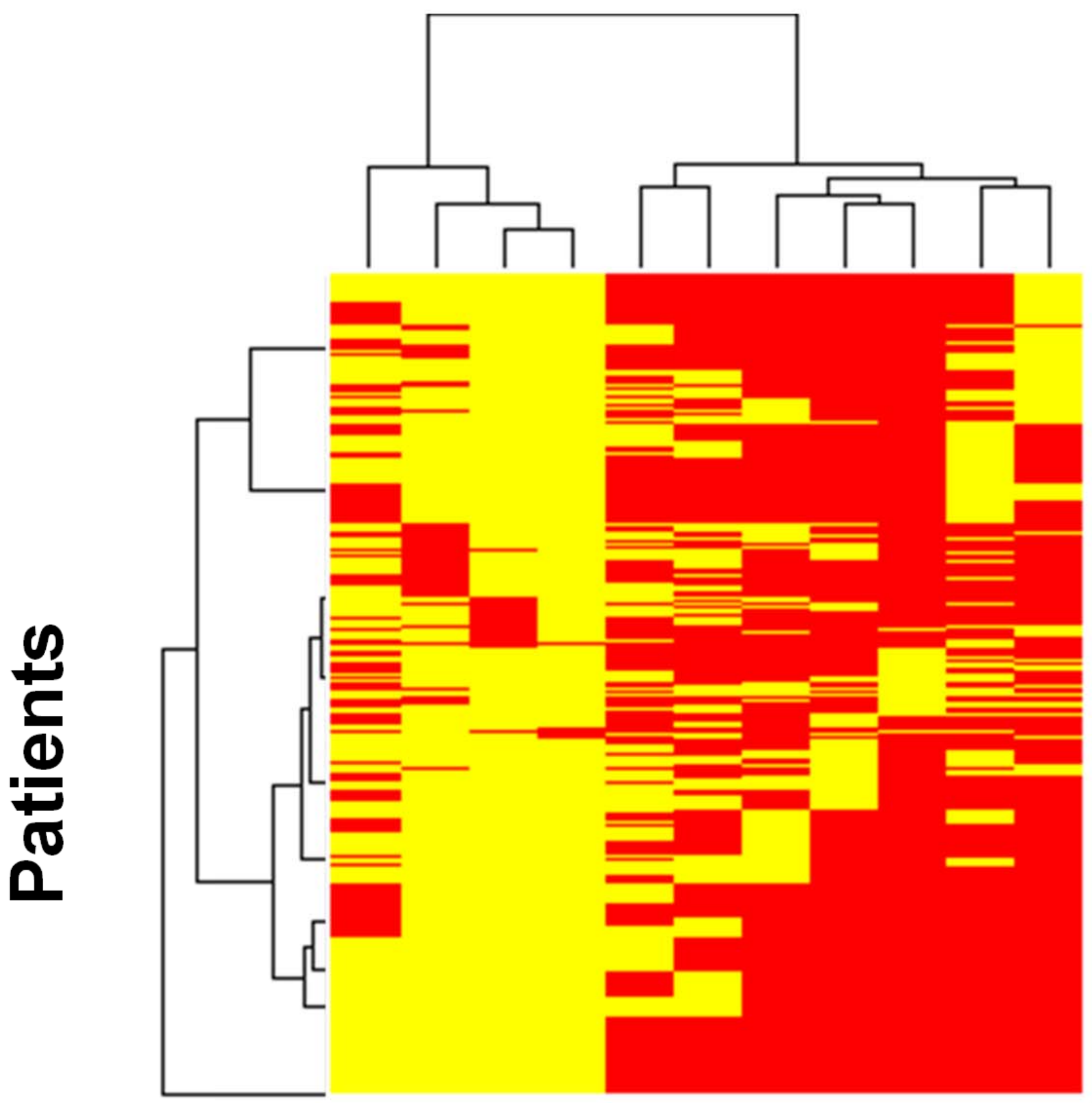




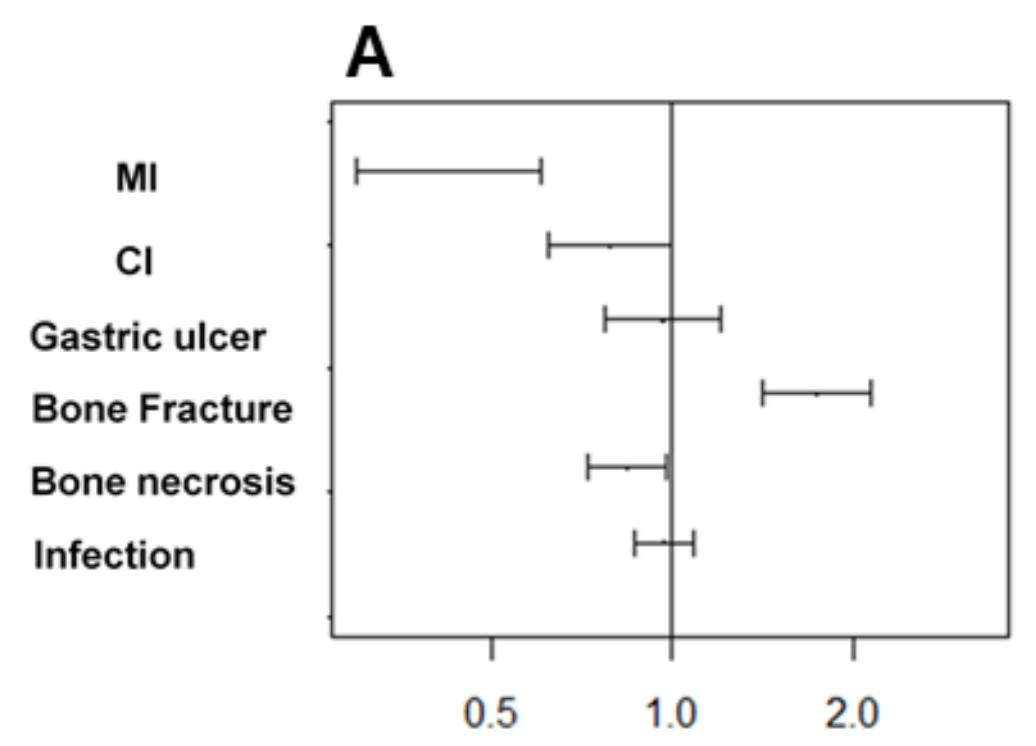

B

C

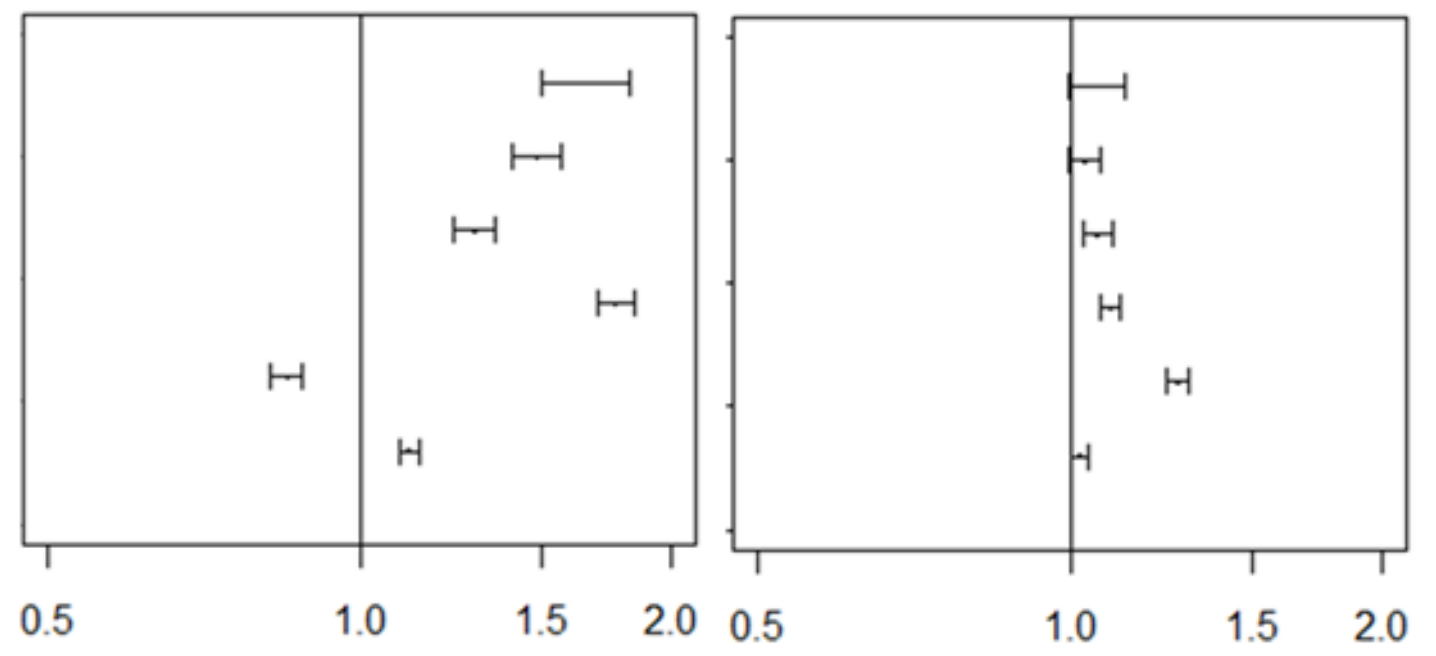

D

E

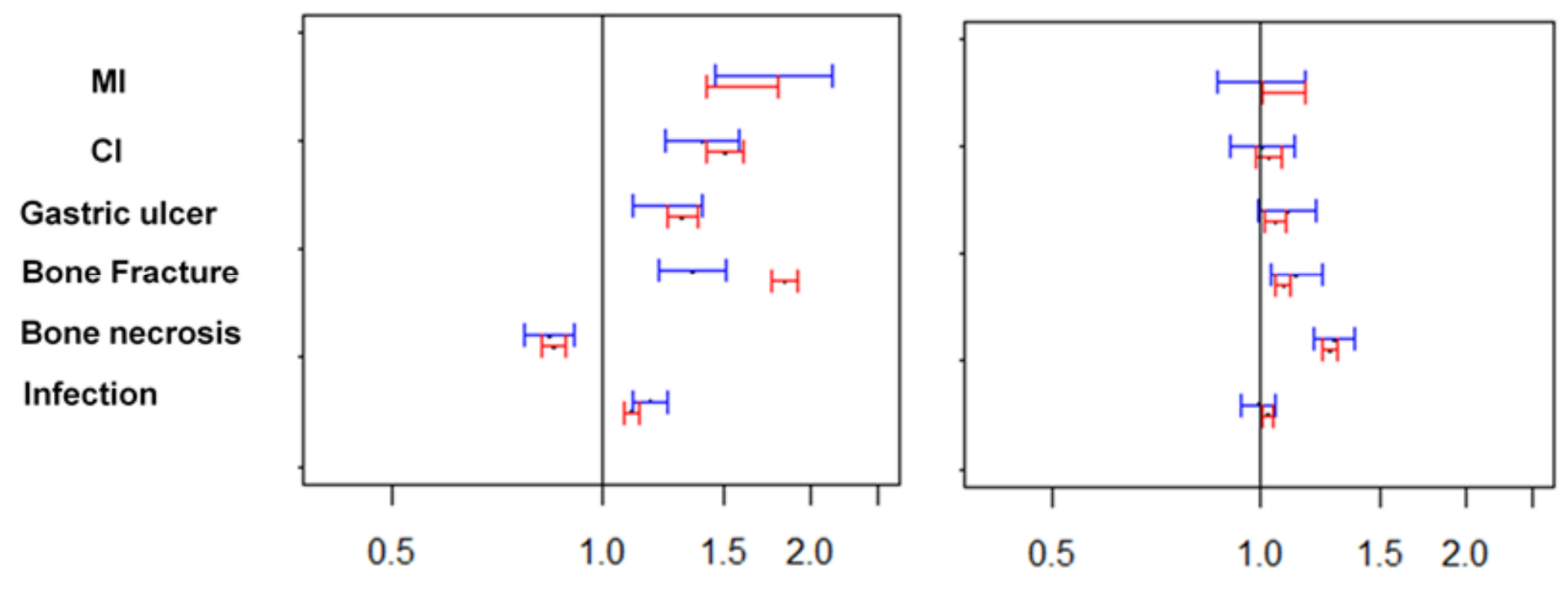

